\title{
Abuelas universitarias: Roles y funciones en la vida profesional y familiar*
}

\section{University grandmothers: Professional roles and functions in the family}

\author{
Lucía Pérez Sánchez**
}

\begin{abstract}
*Investigación realizada para la obtención del título de grado de Psicogerontología. **Doctora en Psicología, Licenciada en Psicología Educativa, Maestra en Terapia Familiar Sistémica y especialista en estudios de género y Psicogerontología. Profesora de Tiempo Completo en el Programa Académico de Psicología del Centro Universitario de Ciencias Sociales y Humanidades de la Universidad Autónoma de Nayarit (UAN), México. E-Mail: lucia@systemica.com.mx

Universidad Autónoma de Nayarit (UAN - México).
\end{abstract}

La autora agradece a la Dra. Graciela Zarebski y a la Maestra Araceli Marconi, de la Universidad Maimónides (Buenos Aires - Argentina), su orientación, asesoría y dirección en este proyecto.

\section{Resumen}

Se informa un estudio cualitativo, cuyo objetivo fue valorar la función de abuela universitaria y profesionista, en la dinámica familiar, desde la propia subjetivad de mujer y explorar la transformación de su identidad, configuraciones vinculares y el legado a las siguientes generaciones. Se hizo un estudio cualitativo exploratorio, transversal y no experimental en el que participaron 10 mujeres voluntarias, de 40 años o más, por inclusión continua por conveniencia, con entrevistas a profundidad y la aplicación del Cuestionario Mi Envejecer (CME). La mayoría de la producción académica en temática relacionada sobre vida académica de las mujeres y su relación con sus funciones en la familia apunta hacia estrés laboral y a la no inclusión en las tareas domésticas del varón, así como la superposición de la mujer en funciones y roles que la sobrepasan, tratando de cumplir perfecta y exitosamente con los deberes laborales, sin faltar a las demandas de la maternidad. Pero sobre mujeres adultas mayores profesionistas y activas laboralmente, no existen referencias de investigaciones. Por ello es de importancia abordar el tema de la abuelidad desde lo femenino, familia, identidades y las configuraciones vinculares nuevas o alternas a las tradicionales. Reconocer la actividad de las abuelas puede motivar en la mejora de la imagen social de las mujeres mayores, contrarrestando la cultura del viejismo.

Palabras clave: Abuelidad; Función familiar; Envejecimiento femenino; Identidades y las configuraciones vinculares.

\begin{abstract}
The following work is the result of an investigation which by its extension - to be a qualitative study - was necessary to be exposed in two parts. This first part presents the theoretical aspects that support the research as well as the methodology used. The second part will present the results and their analysis, derived from the categories that emerged from the in-depth interviews. It should be mentioned that most of the academic production related to the academic life of women and their relation to their functions in the family - although with a broad reflection and sharp analysis with a gender perspective - points to work stress and non-inclusion in the domestic tasks of the male, as well as the
\end{abstract}


overlapping of the woman in roles and roles that pass her, trying to perfectly and successfully fulfill the labor duties and without missing the demands of motherhood. As well an investigation of mature women in aging processes but in relation to the body exploring from perspectives of pathological aging or with dyes towards active and satisfactory aging, being proposals in which the value of doing over the Being of the woman is emphasized. However, it should be noted that there are no references to research on specific adult work in the labor market in different contexts, but on what has happened to the family relationship of the role of the grandmother who is also inserted in the public world, there are no references. The education of women in Mexico, from the time before the arrival of Spain and until the mid-twentieth century, was marked by education for domestic tasks: maternity, home care, child care, and other activities Home care, the history of women's college education contains elements of exclusion and inclusion. Those who at that time gained access to the university developed strategies to overcome these setbacks. For women to enter the university, many struggles had to happen between opposing forces that did not conceive that there were different alternatives for women and not just being a mother and a wife. The first university students entered in careers and placed themselves in professional environments, which did not represent strong confrontations with the conceptions of gender of the time. Thus, their professional and academic achievements reflected the interplay between their desires and what they were allowed according to their socio-cultural context of the historical moment in which they lived. The education of women brought the discovery of their lives, questioning, reflecting, discussing and criticizing their status as women. However, a question arises: Does university life, the professionalization of women, have changed Roles that are played within the family? Are university grandmothers assuming themselves as women conscious of being grandmothers or mothers autonomously and independently of what society expects of them? It is therefore important to address the issues related to the grandparenthood from the feminine, family, identities and the new or alternate configurations to the tradi- tional ones. Thus, the recognition of the activity of the grandmothers can motivate in the improvement of the social image of older women, against subtracting the culture of old. Thus, the purpose of this work was to evaluate the role of university and professional grandmother in family dynamics, from the subjectivity of women and explore the transformation of their identity, their configurations, and their legacy to the next generations. Through a qualitative exploratory, transverse and non-experimental study in which 10 volunteer women, aged 40 years and older, were evaluated by continuous inclusion for convenience, with in-depth interviews, and the ageold questionnaire (CME) was also applied.

Key words: Grandparenting; Grandparenthood; Family function; Female aging; Identities and binding configurations.

\section{Introducción}

Ser abuelo no es solamente un cambio importante en la persona que lo experimenta (con el cual necesitará redefinirse a sí mismo, así como su posición en la familia), sino que también puede ser un factor de influencia de primer orden en el desarrollo de los nietos (Pinazo \& Lluna, 2011).

En este contexto, las relaciones intergeneracionales en general y los vínculos que los abuelos entablan con los nietos, adquieren un interés entonces mayor, ya que en la actualidad el número de personas que llegan a ser abuelos es mayor, así como el tiempo (años) que la convivencia de este vínculo es experimentada, por ello hace necesario realizar estudios, en gran medida de tipo cualitativo, que ayuden a profundizar en características psicológicas que se presentan en esta dinámica relacional (Castañeda, Sánchez D., Sánchez A. \& Blanc, 2004; Castro, 2007; Diale, Longobardi \& Sclavo, 2008; Pinazo \& Lluna, 2011; Rico, Serra \& Viguer, 2001; Ruiz, Pineda \& Valencia, 2009; Sims \& Rofail, 2014; Triadó, Martínez \& Villar, 2000; Wellard, 2013).

Así también, de manera común la abuelidad ha sido asociada a lo femenino, ya 
que tanto los cuidados como el juego con los nietos suelen estar más cerca de lo que se ha caracterizado como actividades femeninas. Sin embargo, estudios recientes muestran como los varones han ido acercándose a roles atribuidos a la mujer (Osuna, 2006).

Si se agrega además el hecho que en el Siglo XXI se disfrutan los logros que trajo el movimiento feminista, en donde la perspectiva de género ha permitido tener una visión crítica de las determinaciones sociales del rol impuesto y modificarlo, junto con las instituciones que lo propician (familia, escuela, iglesia, etc.) de manera que se ajuste a los intereses femeninos (Hierro, 1990), entonces interesa conocer cómo específicamente la educación ha impactado estas nuevas formas de definir el ser mujer y a su vez esto ha modificado los modos de ser abuela y cómo esto implica transformaciones en el tipo de vínculo que se entabla con los nietos. Por tal razón el área que se explora en esta investigación es cómo abuelas que son universitarias y profesionales experimentan esta etapa de la vida, como así también sus interrelaciones generacionales.

\section{La mujer y la educación}

En México, la educación de la mujer desde la época prehispánica hasta mediados del Siglo XX estuvo marcada por la educación para las tareas domésticas: maternidad, atención de la casa, el cuidado de los hijos y otras actividades de cuidado doméstico (Hierro, 1990).

Las mujeres que nacieron en la etapa de la posrevolución mexicana son quienes ven en el otorgamiento del derecho al voto. Las mujeres que se formaron para ser profesoras recibieron una formación dentro de la escuela cardenista: la educación socialista, por lo que la enseñanza en las escuelas rurales las había identificado con el servicio a la comunidad. Sin embargo, aunque otras crecieron en un ambiente de ruptura con las ideas tradicionales aún así, la mayoría de estas mujeres permanecía en el espacio privado, dedicadas a la casa, al cuidado de la familia; acostumbradas a esa exclusión de sus derechos ciudadanos, no vieron los beneficios que tendría con la obtención del derecho al voto.

Para que la mujer pudiera incursionar en el ámbito universitario, tuvieron que pasar muchas luchas entre fuerzas opositoras que no concebían la existencia de alternativas diferentes para la mujer y no solo el hecho de ser madre y esposa. Sólo el movimiento del feminismo abrió la cultura a las mujeres, al concebir: "el descubrimiento, la creación y la práctica de la cultura femenina, que persigue el objetivo político de realizar la revolución de la vida cotidiana... la creación de una educación sin distinción de géneros" (Hierro, 1990, p. 15).

La historia de la educación universitaria de las mujeres contiene elementos de exclusión e inclusión. Las que en ese momento lograron acceder a la universidad desarrollaron estrategias para sortear estos contratiempos.

Las primeras universitarias incursionaron en carreras y se colocaron en ambientes profesionales, que no representaban enfrentamientos fuertes con las concepciones de género de la época. Siendo así, sus logros profesionales y académicos reflejaban el inter juego entre sus deseos y lo que tenían permitido de acuerdo con su contexto sociocultural del momento histórico en que vivieron.

Las mujeres que estudiaban y ejercían su carrera lo eran mayormente en escuelas altamente feminizadas, como enfermería, profesoras, químicas, secretarias, todo este ambiente planteaba siempre la disyuntiva: el matrimonio o la carrera. Aunque siempre existieron las audaces que percibieron claramente las discriminaciones hacia su género y se preocuparon y lucharon de modo activo para cambiar esta situación (Palermo, 2006). Ellas pudieron conciliar ambos territorios e incursionaron en lo privado y en lo público, estos resultados también contribuyen a la memoria histórica, difusión y reconocimiento de la vida de las académicas, sus hábitos e intereses, su vida social, profesional y familiar y la dedicación e in- 
terés que mantienen a lo largo de su trayectoria (Covarrubias \& Brito, 2007).

La vida universitaria de las mujeres trajo por consiguiente la posibilidad de revertir la educación tradicional que condicionaba o condiciona a la obediencia y a la repetición de patrones acostumbrados de identidad de género, les posibilitó también conocer que existen ciclos de vida femenina y que cada uno de ellos requiere una visión de género.

En palabras de González Marín (2015), la educación de las mujeres trajo el descubrimiento de sus vidas, el cuestionarse, reflexionar, discutir y hacer una crítica de su condición como mujeres, ¿qué las mueve en su acción?, ¿cuál es su función en esta sociedad?, ¿qué implica ser mujer?, ¿qué es ser madre?, ¿cuántas etapas recorre la mujer en su vida?, entre otras. Incluso el ser madre, para Hierro (2000), es la posibilidad de construir conocimiento científico: la condición de maternidad en la mujer, cuando se hace consciencia de lo que este momento significa, y se cuestiona y se observa, y no se siguen los patrones establecidos por la sociedad o lo familiar, puede convertirse en la expresión más valiosa de la consciencia femenina.

Desde esta óptica, Hierro propone que tanto la madre como la hija se trasforman en maestras y aprendices, en un intercambio dialéctico de lo que se desea ser como mujer, tanto ser madre como ser hija como un acto consciente de ejercicio de libertad.

Siguiendo a Hierro, surge un interrogante: ¿En realidad la vida universitaria, la profesionalización de la mujer, ha modificado los roles que se juegan dentro del ámbito familiar? ¿Las abuelas universitarias se asumen como mujeres conscientes de ser abuelas o madres de manera autónoma e independiente, de lo que la sociedad espera de ellas, llevando a cabo esa conciencia femenina de la que habla la autora? Por ello es de importancia abordar las temáticas con relación a la abuelidad desde lo femenino, familia, identidades y las configuraciones vinculares nuevas o alternas a las tradicionales.

\section{La configuración vincular familiar de los adultos mayores}

La noción de configuración vincular describe tanto el modo de relacionarse un sujeto con una persona, objeto, institución o ideal, como la circunstancia de ese vínculo en las representaciones y significados sobre el sujeto (Iacub \& Sabatini, s/f).

Las configuraciones vinculares repensadas desde esta compleja plataforma de relaciones y determinaciones, permiten discernir cómo los adultos mayores experimentan los cambios en los vínculos, tanto a nivel de la identidad como en las esferas de relaciones.

"Cada sujeto tiene un mundo interno poblado de relaciones vinculares donde cada uno tiene un papel a desempeñar. Es a partir de estas relaciones vinculares internalizadas (grupo interno) que nos relacionamos con el mundo externo. Leemos el mundo externo desde nuestra experiencia y utilizamos ésta para poder conectarnos con lo enigmático de nuestra cotidianeidad" (Garber, 2006, p. 181).

Mead (1983) sustenta que cada individuo posee un mundo interno rico en representaciones de objetos en el que cada uno está cumpliendo un rol, por lo que hace posible la predicción de la conducta de los demás. En la actualidad con la incursión de la mujer en la vida profesional se esperan (tanto las propias mujeres como el contexto que las observa) ciertas maneras de actuar y modificaciones en funciones familiares específicas, tales como maternidad, vida conyugal, y para el tema que nos compete, formas de ejercer la abuelidad y vivir sus procesos de envejecimiento.

La familia como uno de esos diversos espacios de intercambio que promueven la configuración de vínculos en los adultos mayores es una categoría de agrupación social concebida de muy variadas y múltiples formas según las culturas y momentos históricos, en que se estudie. La familia tiene también diversos fines, lo que le otorga un dinamismo específico y particular; sin em- 
bargo, contiene fundamentalmente la función de protección, procreación y desarrollo de sus miembros (Levi Strauss, 1987).

A su vez, en lo que respecta a las interacciones que se generan en el interior de familia, existen varios espacios de intercambio relacional que promueven la configuración de vínculos intergeneracionales en los adultos mayores, que de acuerdo con lo que describe Mead (1970) pueden darse en tres modalidades, resumidas en la atribución de dos esferas específicas (saber y conocimiento), y las modalidades son: la postfigurativa, la cofigurativa y la prefigurativa (ver Figura 1).

¿Qué implicaciones tienen estos modelos culturales en la relación con el adulto mayor? ¿Qué importancia cobra ante la mujer universitaria y abuela? Esta tipología revela cierto orden de creencias y de atributos de una sociedad frente a las edades del ser humano y lo que se espera en cada una de ellas. Asimismo, permite entender de qué forma se producen modificaciones de cultura generacional, cómo se desarrollan las luchas por imponer saberes y consolidar espacios de poder al interior de un cierto grupo -como la familia- y comprender algunos aspectos de los vínculos: modos de intercambio e interrelaciones.

Los cambios sociales escabrosos pueden generar diferencias internas en los grupos etarios, intensificando las culturas distinguidas por generación. Mead (1970) señala que la cultura postfigurativa, favorece la identidad donde los antepasados son reconocidos por las nuevas generaciones y tienen un alto nivel de determinación sobre los jóvenes. En la cofigurativa existe la connotación de una transgresión real o simbólica de las formas culturas o conocimientos anteriores. Luego de cambios o procesos revolucionarios aparecen nuevos estilos culturales que dividen las diversas generaciones, provocando con ello un tipo de convivencia entre cohortes. Mientras que la cultura prefigurativa favorece la identidad cultural en construcción, es decir, donde el pasado se considera sin continuidad, los padres o antepasados dejan de ser guías, y el presente y el futuro resultan relevantes, por lo que hay que construirlo sin disminuciones.

Es de importancia dar cuenta de estos elementos ya que permite especificar órdenes de creencias que preceden el marco de los encuentros intergeneracionales y que tendrán un alto nivel de determinación, en cualquier encuentro interpersonal.

Así también, las nuevas formas de ser mujer y por ende de ser abuela desde lo que describe Mead, posibilita la resignificación de los vínculos, porque al cambiar los roles tradicionales y las funciones, aparecen nuevas relaciones intergeneracionales, quizá más flexibles, alternas y creativas (Osuna, 2006).

En cuanto a los cambios que trae consigo el rol de abuelos se deben considerar algunos aspectos que menciona Pérez (2007): la abuelidad es una contra transición biológica, dado que no fue una decisión del propio sujeto pasar a esta condición social y rol familiar, sino que depende de otro (sus hijos/as) para llegar a serlo, y que implicará modificaciones en su vida cotidiana. Esta es una diferencia importante en cuanto a la toma de decisiones de la mujer puesto que, para ser madre o profesionista, sin duda ejerció su voluntad, pero para ser abuela no fue así, por lo que esto le da una oportunidad singular para definir, significar y construir su propio modo de ser abuela; regresando con Hierro (2000), es una posibilidad para hacer conocimiento científico.

Este tipo de estudios relativos a la cuestión de la abuelidad (vejez y familia) posibilita comprender en qué medida las modificaciones a los modelos de familia socialmente constituidos inciden en los significados otorgados a los roles de los adultos mayores y sus modos de relación e intercambio (Salvarezza, 1998). Así también el reconocimiento de la actividad de las abuelas puede motivar la mejoría de la imagen social de las mujeres mayores, contrarrestando la cultura del viejismo, en la medida en que demuestra que no son meras receptoras de ayudas y servicios por parte de las generaciones más jóvenes. 


\section{La abuelidad}

La abuelidad desde una perspectiva gerontológica da lugar a las propias habilidades generativas, sirviendo de función reparadora para contrabalancear algunas de las pérdidas que se producen con el envejecimiento.

El conocimiento generado por investigaciones sobre abuelidad y especialmente, la precisión del vínculo y la importancia social de las relaciones entre abuelos y nietos constituye un fenómeno relativamente reciente, ligado al desarrollo de la Gerontología y los derechos de los adultos mayores, así como al fenómeno del incremento en la esperanza de vida (Góngora, 2012; Villalba, 2001; Yerro, 2013).

El rol del abuelo o abuela se sujeta con la transferencia del conocimiento generacional del pasado y de los orígenes, a la vez que, al mantener una relación con los nietos menos tensa por las relaciones de autoridad que ellos mantienen con sus padres, los abuelos se hallan en excelentes condiciones para atender a sus nietos ante la ausencia de los padres.

Esta relación generacional tiene como principal función el proceso de la consecución intergeneracional, el cual está ligado de manera cercana al de la construcción de la identidad (Garber, 2006).

La palabra y concepto de abuelidad surgió por la necesidad de establecer un término que incluyera en la estructuración psíquica individual y familiar, la figura y rol del abuelo, siendo la médica argentina Paulina Redler (1986), quien lo acuñara (Yerro, 2013).

El concepto abuelidad quedó confirmado posteriormente en las publicaciones en español que gradualmente comenzaron a referirse al tema desde el punto de vista histórico social. A partir del año 1996 aparece el término abuelidad en la bibliografía de campos disciplinares en la producción psicoanalítica, gerontológica, familiológica o sociológica en español.

El término abuelidad en la actualidad engloba también un movimiento social, an- clado a lo vivido en la sociedad argentina y las Abuelas de Plaza de Mayo. El peso simbólico, con notoriedad pública de la palabra abuelidad abarca conciencia social de búsqueda de justicia, libertad hasta convertirse en símbolo de la resistencia popular contra el terrorismo de Estado. Así, estas Abuelas, con sus acciones y normativas en pro de la infancia discriminada han llegado a erigirse en un modelo mundial que viene a echar por tierra el mito sobre la edad pasiva (Arditi, 1999; Herrera \& Tenembaum, 2007).

Galeano (2015) menciona que en el Siglo XXI se ensalza la imagen de la mujer que sigue el juego de la postmodernidad, proponiéndola como una mujer libre, de acuerdo a lo ganado en el movimiento feminista. Pero esta relación se invierte cuando la mujer envejece, dado que a los ojos de la cultura occidental el envejecimiento, se aleja del estereotipo deseado. La imagen cambia y el peso de la mirada del otro es implacable. Persisten características que tradicionalmente se le han otorgado a la mujer mayor: fragilidad, declive, pasividad, necesidad de protección. Además, la imagen y presión social demandante de la maternidad como sinónimo de feminidad, se traduce en la vejez, en ser abuela cuidadora, inactiva y dependiente; otra equiparación riesgosa (Frexias, 2008; Holstein, 2006).

Como explica Zarebski (2005, 2008), se debe considerar un factor de riesgo psíquico el construir en un sentido unívoco la identidad, pues esto tiene que ver con un yo ideal que no da lugar a una auténtica realización personal. Es el pasaje a la primacía del ideal del yo lo que simboliza la falta que impulsa al sujeto al futuro. Es absolutamente contraproducente en este sentido, la idea de que la mujer luego de haber tenido hijos ha cumplido con su ciclo, así como los viejos luego de haber llegado a determinada edad.

Por ello en este trabajo se abordará cómo estos constructos sociales siguen imperando en sociedades modernas y académicas. Y si son las mismas mujeres quienes reiteran este legado a las generaciones de mujeres 
más jóvenes, contraponiéndose con el legado que facilitó el origen al concepto de abuelidad sinónimo de activismo social crítico.

\section{La pertinencia de la temática}

Al hacer una revisión de investigaciones previas sobre esta temática específica, aparecen tan solo en las indexaciones científicas alrededor de 410.052 artículos científicos cuantitativos o cualitativos que hacen referencia a profesoras académicas universitarias y sus vivencias o experiencias, tratando de conciliar su vida profesional y la familiar, así como sus aportes al conocimiento, en los que se exponen evidentemente aún desigualdades pero también logros y avances (Red de Revistas Científicas de América Latina y el Caribe, España y Portugal -Sistema de Información Científica Redalyc- consultado en enero de 2017).

Se destaca un artículo (Blanco, 2007), sobre la conciliación del trabajo y la vida familiar de las profesoras académicas en España, sin embargo aunque con un análisis agudo y con fuerte perspectiva de género, aborda la vida académica de mujeres jóvenes en edad reproductiva. Así también se encuentra la investigación de Blázquez y Bustos (2013), en las que entrevista a académicas de México y Cuba, con la intención de conocer sus vivencia y experiencias en su ámbito universitario y específicamente en puestos de gestión y jerarquía, a lo que concluyen que las mujeres que acceden al poder se reivindican como tales, hacen de su herencia cultural una ventaja y buscan armar sus equipos tanto con mujeres como con hombres. Sin embargo, ello no garantiza que ejerzan el poder con una consciencia de género como para transformar las inequidades.

En estas entrevistas también se da cuenta de las condiciones de las profesoras universitarias en Latinoamérica y exponen las diferencias de oportunidades. La autora concluye que se debe indagar sobre las múltiples formas en las cuales lo femenino no está contenido en lo masculino, gracias a las producciones contra culturales y antihegemónicas de las mujeres en América Latina.

La mayoría de la producción académica en esta vinculación temática, vida académica y familiar apunta hacia estrés laboral y a la no inclusión en las tareas domésticas del varón, así como la superposición de la mujer en funciones y roles que la sobrepasan, tratando de cumplir de manera perfecta y exitosa los deberes laborales y sobre todo maternos (Galhardi de Pujalt, 2007).

Sin embargo, cabe destacar que sobre abuelas profesionistas y activas en la vida laboral, post movimiento feminista, no existen referencias de investigaciones específicamente en el mundo laboral en distintos contextos, pero sobre lo que ha sucedido con la vinculación familiar del rol de la abuela que además está inserta en el mundo público, tampoco existen referencias.

Existen investigaciones acerca de la mujer madura en proceso de envejecimiento, sobre todo en lo relacionado con el cuerpo (Calasanti, 2004; Gullette, 1997, 2004; Twigg, 2004), pero desde planos de un envejecimiento patológico o con tintes del envejecimiento activo y satisfactorio que en palabras de Frexias (2008), son propuestas en las que prima el valor del hacer sobre el de ser. Por lo que justifica lo que se pretende explorar y describir aquí: la abuelidad transformadora en sus roles y funciones, y su valoración en el ámbito privado pero que a la vez modifica lo público y viceversa. Y de lo cual no se encontraron aproximaciones empíricas por lo que abre una beta interesante a explorar.

\section{Objetivo}

El objetivo del estudio fue valorar la función de abuela en la actualidad, en la dinámica familiar, desde la propia subjetivad de la mujer a partir de los 40 años y que a la par tiene un rol activo como docente universitaria y profesionista, en la ciudad de Tepic Nayarit (México). 


\section{Método}

La elección del enfoque fue a través de la metodología cualitativa, ya que tuvo como objetivo la descripción de las cualidades de un fenómeno que pueda abarcar una parte de la realidad, y no se trata de probar o medir en qué grado una cierta cualidad se encuentra en un cierto acontecimiento dado, sino de descubrir tantas cualidades como sea posible. Es decir, tratar de conocer los hechos, procesos estructuras y personas en su totalidad, y no a través de la medición de algunos de sus elementos. La misma estrategia indica ya el empleo de procedimientos que dan un carácter único a las observaciones (Taylor \& Bogdan, 1986).

Se realizaron entrevistas semi-estructuradas a profundidad tal como lo define Hernández, Fernández y Baptista (2006) para explorar la transformación de la identidad de la abuela universitaria, sus configuraciones vinculares y su legado a las siguientes generaciones como mujer docente universitaria y profesionista, obteniendo así datos que ofrecieron información para entender la perspectiva del fenómeno estudiado.

Por ello el método está basado en lo etnográfico. Dado el tema y objeto de estudio, que consistió en examinar los modos en que las personas aplican las reglas culturales abstractas y percepciones de sentido común a situaciones concretas, para que las acciones aparezcan como rutinarias, explicables y carentes de ambigüedad. En consecuencia, los significados son un logro práctico por parte de los miembros estudiados (Taylor \& Bogdan, 1986).

El estudio tuvo un alcance de tipo exploratorio - descriptivo pues solo busca especificar las propiedades, las características y los perfiles importantes de las personas o sujetos de la investigación o fenómeno que se sometió al análisis. Además el propósito consiste como lo definen Hernández, Fernández \& Baptista (2006), en describir situaciones, eventos y hechos, es decir, cómo es y cómo se manifiesta determinado fenó- meno y en su diseño el estudio fue de tipo transversal.

\section{Instrumentos}

Se administraron los siguientes instrumentos:

Entrevistas semiestructuradas a profundidad de acuerdo con el modelo de Patton (1990, citado en Rodríguez Gómez, 1996).

- El Cuestionario Mi Envejecer (CME Zarebski, 2011), Versión Menores (Vm: menores de 60 años) y versión Mayores (VM: a partir de los 60 años); para profundizar en la información recabada.

\section{Muestra}

Se propuso un estudio de casos y el método de muestreo fue no probabilístico (Hernández, 2006), trabajando con sujetos voluntarios de inclusión continua por conveniencia, con la técnica de bola de nieve.

Se trabajó con un total de 10 participantes divididos en dos grupos: uno compuesto por cinco mujeres, abuelas y docentes universitarias laboralmente activas de la Universidad Autónoma de Nayarit, y un grupo comparativo que estuvo formado por igual cantidad de mujeres, abuelas, con características sociodemográficas homogéneas, dedicadas al ámbito del hogar únicamente, no profesionales y residentes en la ciudad de Tepic Nayarit (ver Cuadro 1).

\section{Criterios de inclusión.}

Fueron evaluadas 5 profesoras con una edad de 40 años y más, que hubieran ejercido o se desempeñaran aún en su profesión, con una antigüedad mínima de 5 años de labores, y que además ejercieran el rol de abuela con un tiempo mínimo de abuelidad de un año al momento de la investigación.

El grupo comparativo estuvo conformado por 5 mujeres que no tuvieran formación ni actividad profesional, que solo se hubieran dedicado al hogar y que tuvieran como mínimo un año de ser abuelas. 


\section{Unidad de estudio.}

El contenido del discurso, para analizar el material simbólico total obtenido a través de la entrevista a profundidad y los cuestionarios aplicados a los participantes.

\section{Procedimiento}

La investigación consistió en entrevistar a 10 mujeres que se mostraron dispuestas a participar en la investigación. Solo cinco de ellas eran profesionales. Primeramente, se explicaba en qué consistiría, y posteriormente debían leer la carta de consentimiento informado. A continuación, se llevaba a cabo la entrevista semi-estructurada en profundidad, en la cámara Gesell del Programa de Psicología de la Universidad Autónoma de Nayarit. Terminada esta sesión que llevaba alrededor de dos horas, se le entregaba el CME (Zarebski, 2011) según la versión que correspondía, para que pudieran contestarla individualmente y en la privacidad de su casa. Dos de estos cuestionarios fueron entregados vía electrónica porque así lo decidieron esas profesoras dado que era más fácil para ellas, debido a los tiempos que requiere el ejercicio de la investigación y la docencia dentro de la universidad.

En el caso de las mujeres que no eran profesoras de la universidad, se realizó la entrevista en su casa, pero de igual manera el CME, se les dejaba para ser contestado posteriormente.

\section{Tratamiento de los datos.}

La organización y análisis de la información se realizó a través del análisis de contenido de lo dicho por cada participante, en la entrevista semiestructurada y las respuestas a las preguntas del CME. El CME engloba 25 dimensiones, pero para los fines de este estudio solo se tomaron en cuenta 10 dimensiones (ver Cuadro 2) que eran las más relevantes para los objetivos propuestos y estarían en asociación con las categorías de análisis.
La categorización se realizó a partir del marco teórico estableciéndose los tópicos o temas a explorar en la entrevista a profundidad. Cada categoría contempló subcategorías que se correspondían congruentemente y se procedió a su definición operacional, es decir a exponer cómo se encuentra la categoría definida en la realidad teórica, para posteriormente contrastarla con la realidad empírica (ver Cuadro 3).

Con el análisis se llevó a cabo la organización y procesamiento de los datos o codificación de la siguiente manera (Hernández et al., 2006; Strauss \& Corbin, 2002; Taylor \& Bodgan, 1986):

- Extraer los datos que son significativamente relevantes para el objeto de estudio.

- Establecer relaciones de análisis más abstractas que den lugar a conceptos, proposiciones, modelos y teorías.

- Este proceso es un ejercicio interpretativo desde el inicio, cargado de abstracciones y subjetividad.

- Permite fragmentar los datos en unidades analizables.

- Permite llegar de los datos a ideas.

\section{Análisis y discusión de los resultados.}

Derivado del análisis del contenido de las entrevistas y de las respuestas del cuestionario CME surgieron siete categorías con sus correspondientes subcategorías de análisis. A continuación, se describen y se contrastan a la luz de la teoría. También se han agregado extractos de las narraciones de las entrevistas que se consideraron importantes en los que las mujeres participantes, develan la construcción de sus representaciones, creencias, configuraciones vinculares sobre la abuelidad y su contrastación con los modos de ejercicios de abuelidad que se dan en lo cotidiano de sus prácticas, las cuales son exploradas en el CME.

\footnotetext{
Primera categoría: Configuraciones vinculares familiares.

Las configuraciones vinculares son el modo en que los adultos mayores experi-
} 
mentan los cambios en los vínculos, tanto a nivel de la identidad como en las esferas de relaciones. Esta categoría está compuesta por las subcategorías: tipos de interacción y lugar que ocupa la abuela en la familia, asimismo se relaciona con las dimensiones autonomía y dependencia, estrategias de afrontamiento y vinculación intergeneracional del Cuestionario $\mathrm{Mi}$ Envejecer (CME).

Así también este concepto se refiere a lo que se considera como un inconsciente familiar o vincular en donde las historias ancestrales trascienden generacionalmente; en este sentido, es posible observar un inconsciente que desborda los límites de lo planteado por Freud (1916) se pasa de un inconsciente individual a uno de parejas, familias o grupos (Berenstein, 1991).

Desde la teoría sistémica de la familia, la configuración vincular familiar se refiere al tipo de interacción que diferencia a un grupo familiar de otro. Según Minuchin y Fishman (2001) y Minuchin, Nichols y Lee (2011), esta interacción determina la configuración familiar que puede ser rígida, flexible, difusa, o clara y ella está basada en los subsistemas que conforman al sistema familiar. Minuchin y Fishman (2001) y Minuchin, Nichols y Lee (2011) establecen que, si las jerarquías están distribuidas y claramente establecidas de acuerdo con el desarrollo de las competencias de cada integrante de la familia, la configuración vincular será saludable y adaptable a los cambios que el medio exterior le demande. Lo que significa que una configuración vincular familiar saludable, sería en la que tanto la familia como los adultos mayores pueden y facilitan la adaptación a los cambios, sean estos los correspondientes a ciclo vital o a la libertad de elección a cómo se desea vivir determinado rol familiar. Al respecto, en las entrevistas las participantes mencionan lo siguiente:

"La abuela es la matriarca, la que cuida, protege, orienta.... Cuenta historias, preserva el legado, que la historia familiar no se pierda..." (Participante 1: Profesora universitaria).
Esta frase concuerda con lo que describen Sanz, Mula y Moril (2011) y a lo que denominan trascendencia intergeneracional. Este tipo de vinculación familiar llevada a cabo por los abuelos -según los hallazgos de la investigación gerontológica- favorece la calidad de vida del adulto mayor, tal como lo describen Castañeda, Sánchez, D., Sánchez, A. y Blanc (2004) y Ruiz, Pineda y Valencia (2009). Así también lo menciona Orosa (2014) ser abuela es un rol constituyente de identidad en la vejez. Sin embargo bajo la luz de la perspectiva de género, esta frase abona en la representación de significados de roles maternales en las mujeres adultas mayores, que si bien ya han dejado su ciclo reproductivo, es en el resguardo del legado familiar como subliman este acto de dar vida o preservarla (Freixas, 2007).

Continuando con lo referido por Freixas (2007), otro rasgo característico de la maternidad extendida y sublimada a través del ejercicio de ser abuela, es el cuidado y atención de los nietos, que si bien es cierto, esta función se ejerce desde una postura más flexible y lúdica, favorece el bienestar subjetivo y la autoestima del adulto mayor al compensar las vivencias de pérdidas sociales que suelen estar presentes en esta etapa de la vida (González \& De La Fuente, 2008; Sims \& Rofail, 2014; Wellard, 2013). También los estudios han mostrado que esta función de cuidado a tiempo completo conlleva agobio, insatisfacción, estrés, obligación, exceso de trabajo, afectación en el estilo de vida y limitando la vida privada, el cuidado de ellas mismas, las relaciones sociales y las actividades de recreación y de ocio (Sanz et al., 2011). Lo descrito se puede apreciar en el siguiente extracto:

"Esta relación considero que es muy importante ya que en la actualidad con la necesidad del trabajo de los padres, los abuelos participan activamente en las tareas escolares, ayudando a los nietos y en ocasiones hasta recogerlos de su escuela, de esta manera la abuela con su experiencia guía y corrige a los nietos, inculcándoles valores civiles que los padres y maestros, por 
falta de tiempo no lo hacen" (Participante 9: Abuela no universitaria).

Aunque la participante habla en tercera persona y en plural, es decir -asume que este rol lo ejerce en pareja, y no sola- su idealización es como una mujer abuela en un rol de madre y esposa a la vez. Al ejercer su función de abuela, educa a los nietos y educa aún a sus hijos, ser abuela pareciera ser la extensión permisiva de seguir siendo madre (Freixas, 2007).

No obstante, en esta misma frase, se puede rescatar una visión positiva del ejercicio del cuidado y atención -aun siendo una prolongación de funciones maternalesel hecho de asumir las funciones de abuelidad en pareja, da cabida a una nueva representación y significación vincular con sus nietos, lo cual se constata en investigaciones realizadas por Triadó, Martínez y Villar (2000a, 2000b), en la que ponen el énfasis en la implicación en el cuidado de ambos abuelos, y realizan una diferenciación en el ejercicio de esta función, ninguna menos importante que la otra, los abuelos proporcionan conocimiento de la vejez y del pasado familiar, las abuelas ejercen como cuidadoras y se encuentran más cerca de la realidad cotidiana, concordando con investigaciones antecedentes como las de Van Rast, Verschueren y Marcoen (1995).

Asimismo se pueden ver resignificaciones de esta función cuidadora de los nietos, llevada más allá de la mera disposición de tiempo, y en la que queda claro que la etapa de ciclo vital en la que se encuentran estas abuelas, les brinda la oportunidad de autodefinirse como mujeres con un alto valor intrínseco, más allá de los conferidos socialmente a su género, Si bien se saben las portadoras del legado familiar, lo asumen desde una perspectiva activa, cargada de cultura y con un alto grado de autorreflexión critica de sí mismas (Freixas, 2008; Hierro, 2000), así se ve en los siguientes fragmentos seleccionados:

"La abuela ama incondicionalmente... su comunicación es cálida, lúdica y dirigida a valores humanos que alimenten su espiritualidad..." (Participante 2: Profesora universitaria).

"Considero que la abuela es uno de los vínculos familiares más importantes en el desarrollo social de los niños. Porque desempeña un papel de "acompañamiento interesado", una especie de vínculo cómplicemaestro-admirador-cuidador que posibilita la integración de los niños al entorno familiar y social. Con mayor madurez a veces, que los padres, para afrontar el estrés cotidiano, la abuela desarrolla el tipo de maternidad que desearía haber practicado con sus hijos, dice el dicho que uno aprende a ser padre cuando es abuelo..." (Participante 3: Profesora universitaria).

Estos dos comentarios presentan a esa mujer que hace consciente su labor de ser abuela, y se autoobserva y se autocorrige, en esa búsqueda de significado que trascienda, pues se sabe que ella es una pieza importante en el entramado de relaciones en su vida familiar, y porque no decirlo en la vida de otras mujeres; otorgando de forma libre y gratuita, un valor agregado a esta función, denominado en la teoría gerontológica, socialización inversa, la cual se refleja a través de las relaciones con las generaciones más jóvenes, de tal manera que aprenden de ellas, descubren nuevas perspectivas y tendencias y las adoptan sin temor, incorporando a sus vidas nuevas ideas, gustos y valores (Briones \& Tabernero, 2005). En definitiva, se hacen más flexibles, tolerantes y diversas, lo cual enriquece, también, sus vínculos y contactos personales y promueve su disposición a la aceptación de los importantes cambios sociales y familiares con que frecuentemente se encuentran.

Esta nueva forma de asumirse como mujeres y ser abuelas impacta en su percepción de calidad de vida, al apelar a recursos exclusivos que como mujeres han aprendido a generar, restringiendo su vulnerabilidad y convirtiéndolas en personas productivas y activas, más allá del imaginario esperado, de dependencia y pasividad, tal es el ejemplo con el siguiente comentario:

"Hacer ejercicio, procurar comer poco pero sano, leer y ahorrar" [Participante 1. 
Profesora universitaria (Diabética desde hace 16 años)].

La presencia de estrategias de afrontamiento adecuadas, por ejemplo el ahorro, la prevención de salud: chequeos médicos periódicos, atender padecimientos crónicos (adherencia al tratamiento) y también la aceptación de los cambios propios de esta etapa de vida (uso de anteojos y lo que sea necesario para seguir con su vida activa hasta donde sea posible), son una muestra de que la mayor longevidad de las mujeres no se resume en un mejor estado de salud en la vejez, opuestamente, su salud percibida es claramente peor que la de los hombres de la misma edad. Sin embargo, su actitud activa -sus recursos de afrontamiento- frente a la salud es un factor primordial cuando son mayores. A pesar de que la historia del cuerpo de la mujer ha vivido una historia de alienación que regularmente las ha afectado en términos de salud, las mujeres mayores tratan de mantenerse activas y saludables, otra vez contrastando con la creencia de la mujer mayor pasiva y dependiente tal como ya lo han descrito las investigaciones (Cruikshank, 2003; Tannenbaum, Cara, Nasmith \& Mayo, 2008).

Segunda categoría: Significaciones asociadas a la abuelidad.

Esta categoría se refiere a los atributos esperados y que la sociedad ha conferido a la mujer en el rol de ser abuela, los que prevalecen y los que han cambiado. La componen las subcategorías sobre significaciones asociadas a la abuelidad, y los roles sociales de género relacionados con elser mujer y abuela, y estos a su vez se vinculan con las dimensiones Sensación de vejez o sentirse viejo y las Expectativas de longevidad que evalúa el CME.

Constructos subjetivos que han sido aceptados y se repiten de generación en generación o que por lo contrario la generación más joven los desafía y los resignifica en nuevos constructos. Tienen que ver con la experiencia emocional, con la interacción cotidiana y un proceso grupal $(\mathrm{Ka}$ - hana, E. \& Kahana, B., 1971). Al respecto, en las entrevistas las participantes relataron lo siguiente:

"En una sociedad en la que aún tienen gran importancia las abuelas, como una exaltación del simbolismo asociado a la maternidad, pero también como un reconocimiento social al papel que las abuelas han adoptado en muchísimos casos como eje o ancla de la familia..." (Participante 3: Profesora universitaria).

"Necesariamente la figura de la abuela ha ido cambiando, ya no es la abuelita de Cri-Cri, que habla del pasado, las abuelas de hoy hablamos del hoy, de nuestro presente; sabemos que somos fundamentales para que las generaciones de mujeres continúen; imagínate que mis historias de abuela son de mis tiempos cuando estuve en protestas, en movimientos estudiantiles, no puedo ser una abuela normal... Si es que normal es la abuela del reboso de bolitas [esta descripción alude a una canción popular del cantautor Gabilondo Soler, conocido como CriCri y que forma parte del legado cultural contemporáneo mexicano]" (Participante1: Profesora universitaria).

Con estas porciones extraídas de las respuestas de las participantes se puede reflexionar que estas mujeres como profesoras universitarias se asumen como abuelas activas, resignificándose no solo ellas, sino todo un colectivo mayor de mujeres que han decidido de manera libre, la forma de ejercer los distintos roles y funciones que le atañen de acuerdo al momento histórico que viven, (Hierro, 2000; González, 2015).

Es decir, el significado intersubjetivo es ya el de una mujer que redefine sus fuentes de autoestima, extiende el cuidado principalmente a sí misma a través de la participación educativa, reconoce su función de depositaria de conocimientos y habilidades, aprendidos muchos de ellos en el ejercicio del cuidado familiar, y encuentra su valor como transmisora de experiencia y sabiduría vital (Serdio, 2007, 2012).

Cuestionando de manera proactiva, el factor emocional participante durante décadas en el mantenimiento del sistema de 
género, es decir, un sistema determinado por un modelo patriarcal que ha definido muy claramente lo masculino y lo femenino en lo que a roles y emociones se refiere, y donde se le otorgaba a la mujer mayor -en funciones de abuela- una responsabilidad con tintes milagrosos de conseguir la comodidad, armonía, belleza y el bienestar de todos los cohabitantes de la casa, mediante una entrega amorosa de si misma que habría de ser completa y sin cuestionamientos (Rodríguez, 2002). Y la muestra queda manifiesta en los siguientes fragmentos de entrevista:

"Definitivamente la figura de la abuela se está transformando. La abuela ha pasado de ser una persona anciana, dedicada a las labores del hogar -que cocinaba mejor que nadie y que constituía una fuente inagotable de ternura y paciencia hacia toda la familia a la que dedicaba su vida entera- a la mujer con opciones a decidir ya sea para desarrollar una de dos opciones:

- Ser una mujer profesional, con sus propias metas e intereses que no asume el control, ni es el centro de la familia, más una compañera de vida para su pareja, hijos y nietos.

- Constituirse en un accesorio útil para el cuidado de los niños y algo obligatorio que atender.

Si bien persiste en nuestra sociedad el modelo idealizado de la abuela, se puede identificar claramente la emergencia de las otras dos modalidades. Considero que se han presentado porque nuestra sociedad actual ha desmitificado y des-institucionalizado todo, y una de esas cosas es la familia. Con la existencia de familias monoparentales, homosexuales, o por asociación, los familiares han tenido también que cambiar. La figura de la mujer como jefe de familia, que emerge en el Siglo XX se ha consolidado como una entidad aceptada socialmente, lo que requirió desarrollar nuevas funciones y romper el mito de la madre sumisa y dedicada al hogar. Hemos aprendido a vivir sin cuidado de hombre ni protección de marido, como decía una querida amiga mía..." (Participante 3: Profesora universitaria).

“... el significado de la abuela, cambia porque el ser humano es histórico y cambiante, la realidad de ahora no es la misma del Siglo 20. Antes el ropero de la abuela estaba lleno de recuerdos, ahora las abuelas trabajan fuera del hogar, la abuela debe estar actualizada para entender los cambios que viven ahora los niños..." (Participante 2: Profesora universitaria).

De lo anterior, entonces surge una nueva pregunta ¿estas nuevas significaciones y redefiniciones que tienen estas mujeres, tienen un impacto en la sensación de vejez o de sentirse viejas? Al respecto, se pueden encontrar diferencias marcadas entre los grupos, si bien las profesoras universitarias, a la pregunta de $i$ Te sientes vieja? Sus respuestas fueron en el plano de la actividad intelectual, y muy pocas a lo referente a lo físico, las mujeres no profesoras universitarias, fue en lo que mayor énfasis hicieron.

"Al mirarme al espejo veo que ya tengo dientes postizos, uso lentes para ver y algunas canas. Siento que ya no soy la misma" (Participante 7: Abuela no universitaria).

"Sí, me siento vieja, después de una operación de matriz [esta respuesta hace alusión el hecho que posterior a esa intervención quirúrgica, se desencadenó un envejecimiento en sus funciones sexuales femeninas]" (Participante 8: Abuela no universitaria).

"Sí, ahora me dicen que lloro por todo, que por lo tanto ya estoy viejita" (Participante 10: Abuela no universitaria).

"Veo que están llegando los años" (Participante 9: Abuela no universitaria).

Estas respuestas concuerdan con la idealización y significación de la abuelidad en un estado de minusvalía, disminución del componente de belleza física y con la imagen oscura a favor de los modelos que priman la visión del envejecer como el viaje ineludible hacia la enfermedad y el deterioro (Freixas, 2008). Así parece que en estas mujeres específicamente existen situaciones que les generan dificultad en su reconocimiento de la imagen que van 
viendo aparecer conforme transcurre la edad y pueden notarse factores de riesgo para una percepción de envejecimiento patológico.

"La vivencia de un envejecimiento normal o patológico, está dada en relación a la existencia de mecanismos psíquicos que se ponen en juego en este proceso (Zarebski, 2005), es decir, la construcción que se hace de la identidad misma, de la significación que se hace en relación a la fragmentación del Yo, situado inicialmente en el cuerpo, al mirarlo en el otro; ese otro reflejo de la propia vejez anticipada: en el que se construye un proyecto de vejez o se cae en la angustia al vivirlo y experimentarlo como amenaza. Sin duda alguna la vejez cuestiona de manera directa al Yo en lo relativo al proceso identificatorio" (Pérez, Oropeza, López \& Colúnga, 2014, p. 5).

En cambio, en las abuelas universitarias existe la posibilidad de construir la identidad a partir de los cambios que van viniendo con esta etapa, se reconocen como parte de un proceso.

"Sí, sí me siento vieja, aunque eso lo percibo en mi cuerpo, como decía mi abuela: Todo por servir se acaba", pero hay una cosa que no envejece si la mantenemos activa y esa es el alma, a mí nadie me quita el gusto de disfrutar una buena lectura, una rica compañía con mis amigas, una conversación de un tema social o político, incluso de discutir sobre cómo se da mejor una clase que otra... el cerebro no se muere si lo trabajas..." (Participante 1: Profesora universitaria).

En esta frase queda reflejadas las expectativas y condiciones de longevidad, que no tienen que ver con el elemento biomédico, sino que concuerdan con lo que la investigación en Gerontología crítica feminista valoriza: la cercana interrelación entre bienestar físico y psicológico y la insistencia en la importancia de la salud como elemento predictor básico del bienestar en las personas mayores, así como en la función que juegan los ideales positivos en el la vida de las mujeres adultas mayores, como factores de sostenimiento anímico y vital (Gannon, 1999).
Tercera categoría: Identificación con abuelas y legados de la familia.

A esta categoría corresponden los modos con que las mujeres se identifican con mujeres de su linaje y que permiten configurar una identidad que las diferencia como grupo familiar. Es la forma en que se transmite la cultura familiar de manera objetiva (Garzón \& Mendoza, 2007). Las subcategorías que corresponden están relacionadas con la identificación que hicieron las mujeres evaluadas con las abuelas de sus familias, así como el legado que recibieron de las mujeres mayores que les antecedieron, y también con respecto a los aprendizajes que se derivan de la relación con sus nietas. Por su parte, las dimensiones continuidad identitaria y modelos y grados de identificación del CME son las que corresponden de forma congruente para su análisis.

Desde la teoría sistémica, cuando se observa a los individuos que tienen un pasado $\mathrm{y}$ un futuro gregario, se puede ver que se tratan entre sí de acuerdo con formas organizadas de conducta. Si hay una generalización aplicable al ser humano y demás animales, es el ser capaces de aprender a organizarse. Estar organizados significa seguir modos de conducta estandarizados y redundantes y existir dentro de una jerarquía. Las criaturas que se organizan gregariamente forman una escala de estatus o poder en la que cada una ocupa un lugar en la jerarquía, con alguien por encima y por debajo (Minuchin \& Fishman, 2001; Minuchin, Nichols \& Lee, 2011), de esta manera se aprenden o se desaprenden formas de interacción. Al respecto en las entrevistas se puede constatar lo descrito:

"Por supuesto que aprendí a ser abuela, por todas mis abuelas, ellas fueron y son parte de lo hoy soy, no sé si soy una abuela como ellas lo fueron, porque pues sí, a mí me tocó que me cuidaran, eran mamás en todas las áreas de su vida, era lo que se esperaba de las mujeres, los tiempos cambian a mí me tocó ya ir a la universidad, y si algo recuerdo es la mirada de mis abuelas, era como si a través de mí, ellas estuvieran allí 
conmigo en la universidad... no claro, no soy igual, yo no cocino como ellas, es más no me gusta o sí pero no tengo tiempo para dedicarle horas a un guiso soy más práctica.... Ahora que lo pienso, no sé si soy una abuela como ellas, pero bueno que le vamos hacer, esta es la abuela que intento ser para mis nietos.... Mis hijos corrieron por estos jardines [Señala el exterior, la zona verde que se ve por la ventana], y también mis nietos corren ahora; en lo que soy igual a ellas, es que mis nietos son mi sol, yo fui el sol de mis abuelas...." (Participante 5: Profesora universitaria).

Si bien es cierto que el proceso de envejecimiento femenino no solo viene marcado por la continuidad en el rol tradicional de ama de casa y cuidadora, en la actualidad están apareciendo otros formas y escenarios de ser abuela, que conceden a las mujeres mayores el medio para disfrutar de mayor independencia, desarrollo y realización personal. Estas mujeres universitarias que junto con mujeres en nuestro país que se desenvuelven como políticas, líderes sociales y religiosas de edad avanzada pueden dar cuenta de los cambios que se están produciendo paulatinamente, en un andamiaje que relaciona tanto modelos de identificación con figuras de abuelidad, así como aprendizajes en la interacción con las generaciones más jóvenes, tal como lo expresa Ruiz-Alberti:

"Se debe reconocer que los contenidos culturales cambian; por lo tanto nos anima a romper con una idea inmovilista de la edad, que fundamentalmente transmite resignación a las personas, y por el contrario, hay que motivar a las mujeres mayores a que sigan enriqueciéndose social y culturalmente" (2010, p. 21).

Pareciera que la lucha de la mujer comenzara a tener fruto en la generación que hoy le toca ser abuela, como si el linaje femenino a través de estas mujeres abuelas y universitarias pudieran ver a través de sus ojos, lo que ellas por mucho tiempo vinieron sembrando, como lo refiere Hierro (2000) y Frexias (2008), facilitando imaginarios para las nuevas generaciones donde la presencia de la mujer deja de tener un signo de excepcionalidad.

"Si de lo que se trata es de construir nuevas pautas de convivencia, recurramos a nuestras abuelas. Hay una gran cantidad de aprendizaje social que podemos realizar a partir de nuestra experiencia de mujeres y como mujeres. Una experiencia que está poco recogida, que está fragmentada" (Juliano, 2005, p. 30).

Sin embargo, al igual que en otros ámbitos hay que ser conscientes de que el hecho de que haya más mujeres en sitios que no eran comunes, para las abuelas antecesoras de estas mujeres, en ningún caso garantiza cambios de agenda o prácticas desde perspectivas feministas, si éstas no se hacen en consciencia e incluso se les estudia, por eso es necesario combinar la existencia de una reflexión crítica que posibilite el cambio en las nuevas generaciones, aún persiste una memoria colectiva en lo que es aceptado y delegado por las mujeres de generación en generación (Muller \& Bermejo, 2016), por lo que a pesar de los grandes cambios, muchas de ellas siguen en la lucha constante de resistir y ser valiente para manifestar lo que sí y lo que no desean ser.

"Mi abuela siempre fue muy autosuficiente, sabia, dicharachera, alegre, platicona, sociable... Y solo fue a la escuela hasta cuarto año de primaria, pero nunca hubo nada que lo convirtiera en una mujer dependiente económicamente, ni de mi abuelo si quiera" (Participante 1: Profesora universitaria).

"A mi abuela paterna no la conocí. De mi abuela materna, los recuerdos que tengo son ya de una mujer mayor, con una gran trenza que se enrollaba en la cabeza como una corona, a la manera de Josefa Ortiz de Domínguez, que tenía dentadura postiza, la cual se quitaba por las noches y me daba un poco de miedito-asquito-fascinación... Cocinaba de-li-cio-so, no muchas cosas pero los frijoles y la sopa de fideo, jamás me han parecido tan sabrosos como lo que ella hacía. No era una mujer muy afectuosa. Viuda joven, fue cabeza de familia y administradora de sus tierras. Decía que era de 
carácter fuerte y seca en su trato. Para mí fue una figura luminosa porque siempre veía que le brillaban los ojos de emoción al vernos a mis hermanas y a mí, que vivíamos a 8 horas de distancia y solo pasábamos todas las vacaciones con ella. A su manera era cariñosa con nosotros... Pero sobre todo recuerdo que me decía Marga-rosa, porque decía que yo parecía una rosa, que le encantaba platicar conmigo y contarme historias de cuando era joven y andaba de novia, siento que conmigo como con nadie, volvía a sentirse muchacha. Nunca me regañaba, tal vez porque era poco el tiempo que pasábamos con ella, pero nunca la vi como una mujer dura. Recuerdo también que la cuidé en sus últimos días, que la cargaba en brazos y la cambiaba y le daba de comer, y recuerdo que un día antes de morir me reconoció y me vio con ese amor que siempre me hizo sentir. Mi madre fue muy dura y nada afectuosa con nosotros, por lo que el amor de una madre lo sentí de mi abuela..." (Participante 3: Profesora universitaria).

"Creo estoy aprendiendo a ser abuela, conforme voy conociendo más a mi nieta, ella me invita a ser abuela... Claro que mis abuelas me enseñaron, sobre todo lo que no quiero ser, ellas fueron muy frías en sus emociones, creo no es que quisieran serlo, sino que así aprendieron a serlo también, por ello yo no quiero ser así, yo seré muy cariñosa, juguetona, y si mi nieta es poco expresiva, yo la haré bastante expresiva" (Participante 4: Abuela no universitaria).

Es decir, de lo anterior se puede inferir, que así como ellas se identificaron con sus abuelas, aprendiendo de ellas e incorporando estilos y formas a su quehacer de abuela, así ellas se visualizan en una interacción recíproca de continuidad identitaria con sus nietos, tratando de enseñar maneras más flexibles y acordes a este momento social, histórico y cultural que viven, incluyendo a mujeres que no conviven en la vida profesional y académica de la docencia universitaria (Miralles, 2010).
Cuarta categoría: Nuevas formas de ser abuela.

Las nuevas formas de ser abuela son los modos concretos con los cuales las nuevas abuelidades se manifiestan en una sociedad cambiante, pero también son modos con los que las mujeres deciden perpetuar de manera libre roles específicos atribuidos a la figura de la abuela. A partir de lo cual se derivan las subcategorías sobre la identificación particular que la abuela hace de su propio legado que ha decidido dejar a la siguiente generación, es decir, los modos elegidos de manera libre y voluntaria de ser abuela. Las dimensiones del CME que corresponden a esta categoría son las que evalúan la flexibilidad ante los cambios y las trasformaciones, así como actitud reflexiva y expresiva.

Es la vinculación con la consciencia social de que se vive en una época de trasformación, que supone un corte radical con el pasado y es la consciencia de ruptura y discontinuidad la que estimula la aparición de una cultura de preservación, de memoria del pasado común, que se convierte en referencia cultural de la propia sociedad moderna (Ross, 1999). Como puede verse en lo compartido por las entrevistadas en los siguientes fragmentos:

"... Yo como abuela. No me dedico a cuidarlo [refiriéndose a su nieto], me dedico a acompañarlo y disfrutar su compañía. Le enseño muchas cosas, palabras, juegos, a ser ordenado, a ser afectuoso, a respetar, pero no de una manera impositiva. Soy una abuela muy alegre... y muy platicadora. Creo que la mayor diferencia es que me pongo más al nivel de mi nieto..." (Participante 3: Profesora universitaria).

"Creo que lo que convivimos hace la diferencia, hablo con mis nietos sobre la vida, dudas, me preguntan sobre lo que hago en mi profesión, ellos han convivido en mi lugar de trabajo, conocen mi oficina, mis compañeros, platican con ellos, eso creo es lo diferente, hay mucha confianza entre nosotros, incluso me corrigen en como menciono algunos términos modernos, que si el 
WiFi, el whatsapp, etc. Y no me molesta, hay intercambio eso es, hay intercambio entre nuestras pláticas siempre aprendemos algo... y aunque es diferente a como a mi tocó vivir con mis abuelas, al final esto es lo importante la abuela transmite un legado a sus nietos, y que los amo tanto [se llenan sus ojos de lágrimas]" (Participante 5: profesora universitaria).

"Juego, brinco, corro con ella, creo que esto no lo hubieran hecho las abuelas de antes... me canso mucho sí, pero me llena de energía sus visitas" (Participante 2: Profesora universitaria).

"Bueno creo que soy diferente, no me siento vieja, no me siento abuelita, de chongo y reboso, me mantengo en contacto siempre, a diferencia de mis abuelas en las que la relación fue algo distante y fría, bueno más bien muy solemne, muy de reverencia, de hablar de usted, nunca se me ocurriría que podía hablarle por su nombre a mis abuelas, y sin embargo conmigo mis nietos me tienen confianza y hasta me hablan y me dicen por mi nombre; como amigos... Esa es la diferencia mayor que encuentro, no hay tanta solemnidad en mi relación con mis nietos" (Participante 7: Abuela no universitaria).

Ya en el siglo pasado, Neugarten y Weinstein (1964) realizaron una tipología de estilos de ser abuelo/a, y que hasta la fecha sigue siendo uno de los estudios más referenciados, los autores señalaron que existen los abuelos divertidos, formales, distantes, cuidadores sustitutos y portadores de reserva de conocimiento. Esta clasificación la realizaron en base a la valoración de factores que inciden en el estilo que se ejerce y se desempeña en este nuevo rol, y en donde la variable género, ha sido una de las más investigadas y sobre las que más información se posee. Desde entonces numerosas han sido las investigaciones que intentaron clarificar la topografía de la díada abuelo/a nieto/a y las repercusiones psicoafectivas y de desarrollo que tienen para ambos.

Sin embargo, los estudios desde una perspectiva de género -sobre las nuevas formas de ser abuela- concluyen que estas mo- dificaciones son un reflejo de la creciente participación de las mujeres en las instituciones de educación superior, así como su participación en el mercado de trabajo y que por lo tanto, permite la presencia de nuevas identidades genéricas. Cuestionando el rol tradicional, la educación que recibieron fue un instrumento fundamental de toma de conciencia de su propia identidad y con el que conseguir autonomía, individualidad y, por lo tanto, libertad (Serdio, 2012).

Como puede apreciarse en las descripciones elegidas que hacen las abuelas participantes, hay una marcada diferenciación en las formas de relacionarse con sus nietos, se asumen que estas formas son decididas por ellas de ser abuela -el estilo propio- es la contribución a un legado familiar.

Así también se puede apreciar cómo las abuelas se perciben como fuente de amor incondicional, compañeras de juegos, diferenciando el cuidado tradicional con el que ellas han elegido, esto coincide con lo que, Triado, Martínez y Villar (2000) ya mencionan, en relación con la forma de establecer el vínculo de abuela y la edad de ésta. Los abuelos más mayores se perciben en mayor porcentaje como modelo de envejecimiento y ocupaciones, y fuente de comprensión de sus nietos (González et al., 2010).

Manifestando así entonces actitudes y posturas de flexibilidad ante los cambios y las transformaciones que misma etapa de vida les demanda, así como también una actitud reflexiva y expresiva, acentuando la capacidad de adaptación; es decir en algunos casos son respuestas ambivalentes, tanto para el grupo de universitarias como para el de no universitarias; pero fueron más constantes las narraciones a procesos adaptativos y de saberse distintas en algún grado con sus abuelas o mujeres predecesoras.

Quinta categoría: Relaciones intergeneracionales familiares.

Las relaciones intergeneracionales familiares son las que se establecen entre personas de distintas generaciones, que conviven en un mismo tiempo, y que benefician al desarrollo integral. Así, la subcategoría 
pertinente para el análisis fue la que tenía relación con los modos de interacción con los nietos de las mujeres que fueron entrevistadas, así como con las dimensiones del CME que evalúan lo concerniente a la diversificación de apoyos e ideales y las relaciones intergeneracionales que desarrollan las mujeres en esta etapa del ciclo de vida en la que se encuentran.

Diversos estudios dan constancia que los cambios estructurales en la época moderna, han contribuido al llamado fenómeno de la verticalización familiar, es decir, hoy más que nunca diferentes generaciones convivirán juntas (Pérez et al., 2014). Esto brinda la oportunidad para resignificar los modos de coexistencia; siendo así que los abuelos por primera vez en la historia pueden convivir con hijos, nietos y hasta bisnietos.

"Los cambios que la estructura familiar occidental ha ido experimentando durante las últimas décadas (un menor número de miembros por generación por el descenso de la natalidad y una mayor coincidencia de múltiples generaciones dentro de una misma familia debido al aumento de la esperanza de vida), han contribuido a que las relaciones intergeneracionales y, entre ellas, las que se establecen entre abuelos y nietos, hayan tomado una especial relevancia dentro del mundo científico" (Celdrán, 2004, p. 252).

Aunado a ello, Montpetit, Nelson y Tiberio (2016) sostienen que el tipo de relación intergeneracional que se genere dentro o fuera de la familia favorece la mejoría del bienestar subjetivo de las personas mayores y a protegerlas de los sentimientos de soledad (De Jong Gierveld, Dykstra \& Schenk, 2012), por lo que establecer lazos cercanos y que además permitan la diversificación de recursos, apoyos y de ideales o valores, tanto para las futuras generaciones, como para las pasadas resulta importantísimo para el impacto e influencia en un afrontamiento hacia el envejecimiento de tipo saludable.

En las narraciones de las participantes esto queda manifiesto, al detallar cómo es su tipo de relación tanto con sus nietos como con generaciones más jóvenes:

"Mi relación con mis nietos es muy buena como te he venido diciendo, es de amigos, no me cuesta trabajo relacionarme, me ha sido más fácil que cuando fui madre, no sé por qué razón, creo ahora mi rol es mas de apapachar, cuidar, proteger, pero sin esa carga de los padres... somos cómplices, aunque nunca le resto autoridad a sus papás, para eso están... Me encanta que salgamos a pasear, o que vengan a visitarme, pero también en ocasiones les digo, hoy no puedo, voy a salir con mis amigas, o tengo un compromiso en la universidad, o simplemente en ocasiones también me atrevo a decirles, no puedo estoy cansada fue un día o una semana pesada (esto pasa siempre a finales de semestre... ellos ya saben, como me pongo)... te digo tengo mucha confianza con ellos y no pasa nada..." (Participante 5: Profesora universitaria).

"Lo cuido formalmente - en forma compartida con su abuelo y su otra abuela, dos o tres tardes por semana. Pero además siempre que puedo me lo llevo de compras, a fiestas familiares o a la playa (dos veces por semana por lo regular). Lo que hacemos todo el tiempo es que jugamos (ya tengo una tendinitis rotuliana por andar tanto a gatas y en cuclillas), leemos libros, aprende a usar mi iPad y mi computadora, le damos de comer a sus gatos, lo pongo en la bañera a jugar con agua, vamos al parque, corremos, nos escondemos, en fin, paso unas tres horas super divertida... y agotada! Bueno, también le doy de comer y lo acuesto a dormir, porque mi hija no vuelve hasta las nueve de la noche" (Participante 3: Profesora universitaria).

"Seré sincera, no quiero ser la abuela ruda y que le tengan miedo, o que sea la abuelita que siempre está trabajando y de prisas, no, es mi responsabilidad acercarme a ellos, yo soy quien debe propiciar la relación, ellos son chiquitos, aprenden de los adultos" (Participante 7: Abuela no universitaria).

"Disfruto su compañía, tengo dos nietas mujeres y un nieto hombre, este fue el primero... Son tan diferentes cada uno, que 
debo ser diferente también como abuela... Pero a todos los amos, de manera diferente, pero los amo... cada uno también conmigo tiene una relación distinta... No sé cómo explicarte, bueno si eres madre me entiendes, cada persona es distinta por eso no puedo decirte con exactitud como es mi relación con mis nietos, porque con cada uno es particular... Si algo agradezco a la vida es esto, ser abuela es hermoso..." (Participante 9: Abuela no universitaria).

"Me gusta hablar con ellos, que me platiquen sus alegrías, sus preocupaciones, sus deseos, y solo quiero complacerlos en todo" (Participante 1: Profesora universitaria).

"No, mi vida no es monótona, por el contrario, hoy en la noche me voy a reunir con unos amigos para celebrar el gusto de estar juntos y planear unas actividades... Mi vida no gira en ser solo abuela o madre, o profesora, tengo muchas maneras de ser" (Participante 6: Profesora universitaria).

De igual manera los comentarios destacados, también tienen una coincidencia con los estudios que se describen en las pasadas categorías, en donde se enfatiza que las nuevas abuelas están resignificando sus formas de establecer su relación con los nietos, $\mathrm{y}$ esto se vive no solo en la intimidad de la vida familiar, sino que también se hace presente en otras esferas sociales de estas mujeres entrevistadas, poniendo el acento en el cómo experimentan este momento de su vida: ser abuela, estar en proceso de envejecimiento, ser mujer, entre otras.

"No se trata de romper con el pasado, según he podido deducir de lo que manifiestan las mujeres, sino de reconducirlo, de aprovechar la experiencia y potenciar lo positivo en un nuevo espíritu amplio, generoso, capaz, entusiasta, lúcido". Esta mirada tiene en cuenta, por ejemplo, que: "Nuestro presente es un conglomerado de cosas excelentes y cosas tremendas, en el que todas suceden a la vez y configuran una enriquecedora complejidad" (Riviere, 2000, p. 35).

En resumen, a la hora de valorar el proceso de envejecimiento femenino la vivencia personal y la manera de afrontarlo son factores decisivos que van a incidir en la fórmula personal con que cada mujer lo enfrentar. En este sentido, los factores educativos, las experiencias de aprendizaje, el entrenamiento personal, la relación intergeneracional y con el entorno, las motivaciones vitales, el estado de salud y económico van a ser variables mucho más decisivas que la edad (Freixas, 2005).

Sexta categoria: Relaciones con otras mujeres contemporáneas (Familia y ámbito profesional).

Las relaciones con otras mujeres contemporáneas se refiere a cómo se organizan, se apoyan, propician el intercambio de experiencias, con el propósito de generar vínculos que les provean conocimientos que ayudan a trasformar modos específicos de convivencia. Las subcategorías correspondientes son las que permiten explorar el tipo de redes de apoyo que se generan entre mujeres y como lo vivencian las entrevistadas. Así también, en el análisis de las dimensiones del CME se identificó su relación con la diversidad de apoyos y la actitud reflexiva expresiva de cada participante.

Esta categoría se refiere al concepto de sororidad, concepto que alude a la posibilidad de resignificación y coexistencia entre mujeres. Nace en el seno de los movimientos feministas y es un aporte de una figura académica referencial del feminismo contemporáneo como lo es Lagarde (1997, 2006). Y no se suscribe solo al ámbito familiar, sino a todo escenario en donde las mujeres tengan convivencia o interrelaciones.

"Desde la perspectiva feminista surge el término sororidad. Esta palabra se deriva del latín soror, hermana, e -idad, relativo a la relación paritaria entre mujeres. Es decir, se trata de una alianza entre mujeres que propicia la confianza, el reconocimiento recíproco y el apoyo" (Martínez, 2014. s.pp).

Las mujeres por naturaleza han desarrollado recursos que en la edad mayor se convierten en poderosas fuentes que limitan su 
vulnerabilidad, estas fortalezas son las redes de amistad, vecindad y comunidad que se presentan como espacios de apoyo y solidaridad -o mejor dicho de sororidad- con el cual pueden dar o resignificar su sentido de vida, en un tiempo -como es el proceso de envejecer- en el que se hace necesario reorganizar y diversificar la escala de valores, de ideales (Coria, Freixas \& Covas, 2005).

"... la mayoría de la mujeres de mi familia, es decir, mis compañeras de generación: primas y hermanas fuimos universitarias, en mi familia no hubo eso de "como mujer debes casarte y tener hijos"... afortunadamente siempre se nos insistió en que a través de la educación es como la gente se supera, aunque no todas decidimos lo mismo, unas se casaron y se dedicaron al hogar, yo no, no me esforcé tanto para acabar partiendo cebollas y limpiando una casa; pero aún así nos respetamos y queremos mucho, siempre creo nos mostramos solidarias ante cualquier problema familiar..." (Participante 5: (Profesora universitaria).

Una de las características de la sororidad es que agrupa a las mujeres, no importa cuales sean sus historias o sus formas de asumirse, la sororidad genera esa unión comprensiva y de acompañamiento solidario de género, aún cuando sea totalmente antagónico la manera de enfrentar la vida. La socialización de género ha facilitado las conductas de cuidado y atención, cuestiones claves para una vivencia positiva en la etapa de la vejez (Freixas, 2008).

"Bueno, esa es una pregunta difícil, de mi edad solo primas tengo, soy la hija mayor; y mi relación con ellas es buena pero distante cada quien está muy concentrado en sus cosas, su familia, convivimos en eventos familiares, y sí siempre tienes más afinidad con algunas y con otras es más educación que vínculo, pero creo que de mi parte si ocuparán algo por supuesto que apoyo, somos mujeres, es nuestra naturaleza creo..." (Participante 7: Abuela no universitaria).

Estos vínculos con otras mujeres proveen conjuntamente, una gran actividad e implicación, tanto en la propia vida perso- nal como en el cuidado de la comunidad creada con otras mujeres. Por ello para las teóricas de los estudios de género, la sororidad constituye la esencia de la ética femenina -a la par de ser un proceso de empoderamiento- porque favorece la crítica reflexiva de la construcción social y cultural de ser mujer, sea niña, joven o en nuestro caso mujer grande, como lo diría Hierro (2000), llegar a ser una mujer mayor en este tiempo histórico, social y cultural, es llegar al tiempo que ofrece esperanza, pues por primera vez en la historia de la mujeres mayores se vinculan y se expresan como sujetas de su propia historia, protagonistas y agentes activas de su madurez, de su vejez e incluso de su muerte (Witt, 2005).

"Definitivamente esto es más fácil [hace referencia a su convivencia en la universidad con colegas], casi se puede decir que veo más a ellas como mi familia, convivo todos los días, conozco sus problemas, crisis por las que han atravesado, y en la medida que puedo ayudo, aunque sea solo escuchándolas; aunque no quiero pintar un panorama fantasioso, hay también mucha competencia, pero creo no somos nosotras, es el sistema en el que estamos inmersas lo que hace que entremos en esa dinámica, la cuestión es que pasa desapercibido, yo me he dado cuenta, me observo, me veo y si es doloroso confesarlo, también no he sido solidaria con otras mujeres, porque no me conviene o porque no encuentro nada que me identifique; sin embargo con otras no ha sido así..." (Participante 5: Profesora universitaria).

"En una ocasión me dijeron que en los trabajos no hay amigas, si es verdad debes cuidarte, pero si tengo amigas, si sí tengo amigas, pero la familia es diferente, creo ser más leal a las mujeres de mi familia..." (Participante 1: Profesora universitaria).

"Sí soy muy activa socialmente con otras mujeres, participo en actividades grupales: grupo de ejercicio, de natación, de literatura, amigas, siempre amigas y hermanas... Si fuera necesario, buscaría apoyo en otras personas y en mis compañeras, de hecho, lo 
busco, tengo distintas redes de apoyo (Participante 6: Profesora universitaria).

Esta categoría revela una gran capacidad reflexiva de las participantes entrevistadas sobre sus propios procesos que como mujeres están viviendo, y pone de manifiesto la necesidad de dar a conocer la complejidad que conlleva envejecer, y envejecer siendo mujer, esto constituye uno de los retos de la Psicogerontología en el plano de la investigación, puesto que muchos de los factores que hasta el día de hoy han caracterizado a la mujer mayor, se están modificando sustancialmente y esto será mayor en las siguientes generaciones (Freixas, 2008), tal como lo expresa esta profesora universitaria:

"Muchas preguntas las había reflexionado ya, sin embargo escribirlas y narrarlas junto con otra mujer, me generó mayor objetividad en lo que está siendo vivir este proceso de envejecimiento... te agradezco que hayas pensado en mí para participar en esta investigación" (Participante 5: Profesora universitaria).

\section{Séptima categoría: Creatividad y gene- rosidad.}

Creatividad y generosidad son los sentimientos de amor y gratitud por lo vivido, $\mathrm{y}$ el deseo de trascender dejando un legado en la siguiente generación. Esta categoría se refiere a la trascendencia simbólica, es decir, el permitir a las generaciones siguientes la continuidad de las tareas, pasar la estafeta, sensación de satisfacción con lo alcanzado, $\mathrm{y}$ es uno de los rasgos a valorar para determinar si existe un envejecimiento patológico o saludable, desde la perspectiva de la Psicogerontología (Zarebski, 2005). Por ello, la subcategoría congruente a esto fue lo relacionado con los modos con que las mujeres evaluadas visualizan la manera en que la siguiente generación vivirá y aprenderá de lo que ellas dejan como legado, y cómo esto se relaciona con las dimensiones expectativas y condiciones de longevidad, autonomía y dependencia, y con la actitud reflexiva y expresiva, evaluadas en el CME.
En referencia al envejecimiento y las nuevas formas de ser mujer, esto querrá decir una manera distinta de asumirse, identificarse con otras mujeres, que ayude a que las siguientes generaciones cosechen lo que con gran esfuerzo estas nuevas abuelas trabajaron, mujeres que vivieron la era de surgimiento del movimiento feminista, la píldora anticonceptiva y la leche maternizada, factores que propiciaron el escenario para grandes cambios sobre el ideal reduccionista de la mujer maternal (Freixas, 2007).

"Bueno algo que tengo claro es que no seré eterna, pero que cada momento de la vida, es una oportunidad para aprender algo, y eso es lo que me sucede en esta etapa, la sensación es de volver a ser niña, y realizar con mis nietos lo que me quedo pendiente.... Ves, la vida te da siempre la oportunidad..." (Participante 7: Abuela no universitaria).

"Considerando que mi hija ve como interactúo con su hijo y le gustan mucho las cosas que hago con él, creo que está también aprendiendo a ser una abuela como yo. Que ante todo ve a los nietos como una fuente de regocijo" (Participante 3: Profesora universitaria).

"Cuando voy con mi madre, le doy la mano para ella baje los escalones. Cuando voy con mis hijas, ellas me dan la mano para que yo baje los escalones" (Participante 6: Profesora universitaria).

"Me retiraré en un tiempo próximo, amo lo que hago en mi profesión, pero sé que debo retirarme, no porque me asuma vieja, no me siento así [aquí hace referencia a perder capacidades cognitivas]; pero creo que ya es tiempo de hacer cosas diferentes, quiero disfrutar de viajar, escribir por escribir, platicar con mis amigas... Quiero salir de mi vida rutinaria con lo que respecta a mi profesión." (Participante 5: Profesora universitaria).

"Ver a mi familia, lo que se quieren y lo unidos que son, será mi balance y diría 'Qué bonita familia me tocó' y me siento muy orgullosa de ellos" (Participante 9: Abuela no universitaria).

Los comentarios destacados confirman lo que expone Burin (2000, p. 3): 
"Entre las abuelas transicionales y las innovadoras también podemos hallar los así llamados deseos nómades deseos variados, diversos, que incluyen experiencias a partir de representaciones genéricas variadas, no dicotomizadas femeninas o masculinas; así como deseos que habrán de ser desplegados mediante representaciones no sólo en el ámbito privado, como en las abuelidades tradicionales, sino también en el ámbito público, no en un único espacio subjetivo y social, sino en todos aquellos que enriquezcan el vínculo entre abuelas y nietos. Son deseos sin un centramiento, sin una focalización estricta, que fluctúan entre diversos objetos".

Las mujeres de hoy se perciben como una generación de trasformación, radicalmente diferente de sus propias madres, pero también de sus hijas cuyo futuro culminará, estableciendo, el camino que ellas iniciaron, lo que puede valorarse como una actitud reflexiva y expresiva, así como de generosidad ante el propio proceso de envejecer.

Muchas de ellas son las iniciadoras de un nuevo linaje femenino, por lo que las hijas y las nietas son las depositarias de ese deseo de continuidad en un futuro que solo podrán realizar a través de lo que alcancen la generación más joven de mujeres que vienen caminando atrás y a lado de estas nuevas abuelas (Sontag, 1982).

De igual forma en lo concerniente a los sentimientos de vejez, expectativas de longevidad, de autonomía o dependencia, en sus relatos puede percibirse la sensación de satisfacción y de gratitud por el momento que a ellas les toca contemplar, es decir, recoger el fruto de un trabajo arduo. La idea central que transmite esta generación de mujeres a la siguiente -a sus hijas y nietases que lo principal, por lo que ellas tanto trabajaron, es su propia autonomía individual concretada en su capacidad para mantenerse a sí mismas.

Esto no es algo menor, se trata de un proceso de resignificación colectiva del que se sienten y son parte y que vincula a las mujeres de ahora con las de otras épocas que iniciaron el camino y también con las generaciones más jóvenes, abonando nuevamente a la idea o concepto de sororidad descrito con anterioridad (Tobío, 2002).

En resumen, el análisis y discusión de los resultados de las categorías descritas anteriormente, muestran que si bien las abuelas de hoy en día sean universitarias o no universitarias, están vivenciando trasformaciones en sus modos de ser y de asumirse como mujer en función de abuela, sin embargo puede notarse una diferencia en las mujeres universitarias por su acercamiento a la formación educativa superior y el desempeño profesional, el cual les ha brindado mayores recursos y oportunidades de reflexión crítica de su condición de ser mujer y por ende su ser mujer mayor en funciones de abuela.

Así también el ámbito académico les brinda a estas abuelas universitarias, el campo propicio para el cultivo de una imagen de mujer mayor mas allá del plano del cuerpo físico, generando una resignificación del propio proceso de envejecer. Sin embargo, esto no es el común mayoritario del colectivo femenino, por lo que inspira a la investigación como a la reflexión teórica empírica sobre la necesidad de llevar estas temáticas a la conversación, al diálogo, a la reflexión en conjunto de las mujeres (sean universitarias o no), en aras de la construcción conjunta de un entramado de experiencias y saberes y así enriquezcan su legado generacional, construyendo una cultura de la sororidad (Kubissa, 1995).

\section{Conclusiones finales}

Las abuelas universitarias ejercen un tipo de configuración vincular tradicional al de la mujer maternal, sin embargo es clara la existencia y la disposición a construir la propia identidad en continuidad a través de los cambios obvios de la edad, es decir, se alejan del significado de abuelidad sinónimo de pasividad y dependencia, se asumen como abuelas activas y en constante autorreflexión de sus funciones y roles con los nietos, en concordancia con los mo- 
mentos históricos que como mujeres les tocó vivir.

Las abuelas universitarias son las mujeres que tuvieron la oportunidad histórica de cuestionar y romper paradigmas, y esto se ve reflejado en su identificación con el linaje femenino de sus familias, tienen claro lo que no desean repetir, pero también tienen claro lo que sí quieren y que deciden elegir como suyo, por ende darle su acento personal en el entramando familiar, haciéndolo manifiesto en las nuevas formas que han encontrado de relacionarse con sus nietos.

En las abuelas universitarias puede observarse un cambio en el significado intersubjetivo de ser abuela y que se ve reflejado en sus sensaciones de ser vieja así como sus expectativas y condiciones de longevidad, su función de abuela se ve enmarcada por lo que han ido construyendo con el paso de los años en su ámbito profesional y docente, quizá el estar en un contexto académico favorece la germinación de esta manera de verse y de reflexionarse a sí mismas, y de alguna manera la facultad al desarrollar más plenamente una especie de competencias socioemocionales, que permiten que puedan experimentar esta etapa de vida con mayores recursos (Mikulic, Radusky \& Crespi, 2015).

No así en las abuelas no universitarias en donde aún persisten los sentimientos de minusvalía y pérdidas ante el paso del tiempo, es decir a estas mujeres les cuenta más trabajo desfigurar ideas heredadas de otras generaciones en donde ser viejo es sinónimo de pasividad.

En las abuelas no universitarias, los cambios son menos notorios sin embargo, pueden apreciar cambios en sus formas de asumir su función de abuela. Se observa su vinculación intergeneracional, no como una responsabilidad solo de ellas sino en conjunto con la familia y la pareja, y con intercambio en los roles específicos de su género, es decir la mujer puede ser más competitiva y activa y el hombre puede experimentar funciones de cuidado y de acercamiento emocional con los nietos.
Las modalidades diversas y de trasformación de asumir la forma de ser abuela, son un reflejo de los cambios que se han vivido en esta época posmoderna, la inserción en el escenario público de la mujer ha provocado que puedan resignificar y contribuir con estilos nuevos, si bien es cierto nuevamente aquí queda claro que el acceso a la educación superior y al mercado laboral ha roto paradigmas tradicionales en el rol que desempeña la mujer en la sociedad, aun en las mujeres que no tuvieron la oportunidad de ir a la universidad se puede ver una ruptura en los patrones acostumbrados a ver en una abuela.

Ambos grupos de mujeres entrevistadas rescatan los modos tradicionales aprendidos de sus propias abuelas, pero haciendo cambios acordes al tiempo que viven. El rasgo más destacado es en cuanto a su cercanía y libertad de expresar sus sentimientos, reduciendo la percepción de la figura de la abuela lejana, altamente reverenciada y en ocasiones, temida.

De tal forma ambos grupos vivencian y propician sus relaciones con sus nietos de formas más igualitarias y democráticas, sin el halo de solemnidad que ellas vivieron con sus abuelas. Esta manera de asumirse como abuelas posibilita formas protectoras antes las pérdidas que se viven en esta etapa de vida, es decir, la posibilidad de vincularse con las generaciones más jóvenes, de manera más flexibles y diversas, propicia el campo fértil para contar con diversidad de apoyos y recursos intergeneracionales.

Así también, para las abuelas universitarias, como para las no universitarias, el apoyo de otras mujeres en su vida es muy importante, y un recurso con el cual se limita su vulnerabilidad de género, pueden existir desacuerdos en cómo se vive y se enfrenta la vida, pero el hecho de ser mujeres las hace unirse y pensarse en colectivo. Por ello, este es el hallazgo más importante que se subraya de esta investigación, ya que aunque se saben solidarias, y han implementado diversas formas de manifestarla, es necesario el reconocimiento de estas formas, dialogarlas y llevarlas al plano de la re- 
flexión, hacerlas visibles a ellas mismas no como cualidades naturales e intrínsecas femeninas sino como un acto altamente ético político de empoderamiento y resignificación profunda de la mujer, y sobre todo de la mujer en el proceso de envejecimiento.

Finalmente, tanto en un grupo de abuelas como en el otro, se aprecian similitudes, ambos grupos asumen que tiene un legado que dejar a la siguiente generación. Aunque ciertamente, las mujeres universitarias tienen mayores recursos y capacidades de reflexión crítica sobre como desean hacer esa trasferencia, y lo que ellas harán al salir del escenario y dar paso a la nueva generación, en una muestra de alta capacidad creativa y de generosidad.

Por lo que, al finalizar esta aproximación exploratoria del tema, queda claro que figura un espacio para abrir una reflexión más profunda. A años de logros en derechos e igualdades en el plano público de la vida de las mujeres, aún queda por trabajar y es- tudiar el ámbito privado de ellas y sus experiencias de vida con otras mujeres.

Al respecto, y continuando con esta investigación, se está trabajando ya desde un diseño socioconstruccionista, basado en los modelos de la narrativa de Michael White y el modelo colaborativo de Tom Anderson, un proyecto denominado Sororidad en los procesos de envejecimiento, y que hasta este momento lleva ya trabajados dos conversatorios dialógicos colaborativos.

El objetivo general de los conversatorios con mujeres (académicas y no académicas) es realizar un ejercicio de auto-reflexión con sentido crítico sobre la experiencia de ser mujer en proceso de envejecimiento. De tal manera que se generen nuevas formas de comprensión de la experiencia que están viviendo, y que todo ello contribuyera a generar una ampliación de alternativas que resulten en trasformaciones de su realidad con un impacto favorable y beneficioso en sus vidas. 


\section{Postfigurativa}

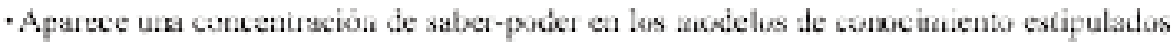
por los antscesores, to que podria denominarse tradición. Son culturas en las que los cambics son tan lentos a impereeptibles que un abuelo abzonds a su nists puede imagiral su futuro. perisando eri su propiz vida ( Meod. 1970).

\section{Cofigurative}

- Este model se origina en una ruptura, que puede producirse por divarx.ss motiwas, nero que cartan oos una continaidad en la que al grupo genericional diminanta porecters perder los usos tel saber que eran hasta entonces una herramienta de poder (Mead. 1970 !

\section{Prefigurativa}

- crestuye una prepuxsta merisuica ya que el saber aparece ubicado en tl que vendrá. Siendo los jóvanes los más favorecidos en esta partida. Mead abica este modelo cultural en momentigs de urisis sciciales profundas, donce se proüucen pérdidas de referentes.

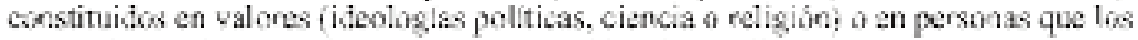
antocediem, limitanto los niveles de seguridad, lo que lizsa a uta apuesti: por bo gue vendía o lo que fepresenta el runurn ; Meixi, $19(x))$.

Figura 1. Tipología de culturas de acuerdo con la atribución de saber y conocimiento.

\section{Cuadro 1}

Datos sociodemográficos de las participantes

\section{Crepe I}

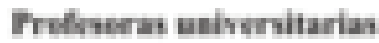

Folat

Fiata dill

Mapalia

\section{Enrw los St y las then \\ Dem nhal mustris:}

I con coptialded mblica

Iem destwrab

1 riuls

Introtus

Dunith libe

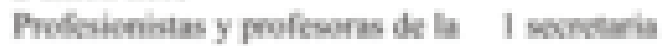

whersids
Grapd

\section{Grupe dh cenirasit}

\author{
40 aths y 67 inth \\ 1 om mustris
}

\section{2 con stales de pinuri}

Icon natedrn de huchillaris

5 cansly:

4 amus dh the 
Cuadro 2

Dimensiones elegidas del CME (Zarebski, 2011)

\begin{tabular}{|c|c|}
\hline Ihmanalin & INthikin todria \\
\hline 1. Tentinuldad Hentitaria & 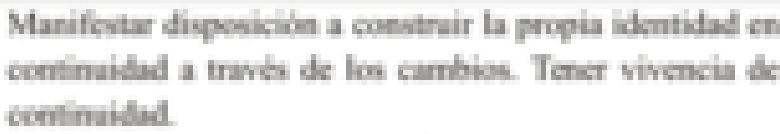 \\
\hline 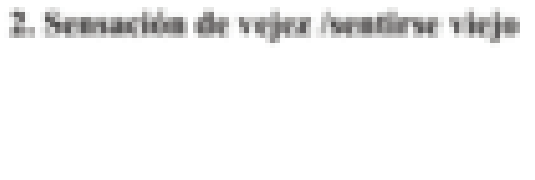 & 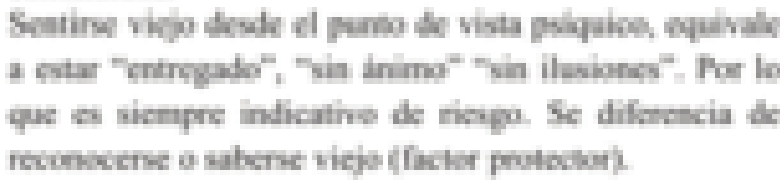 \\
\hline 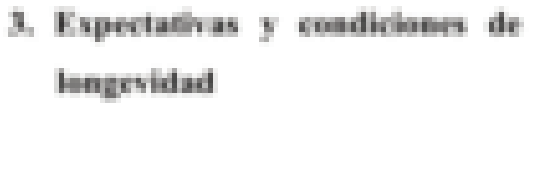 & 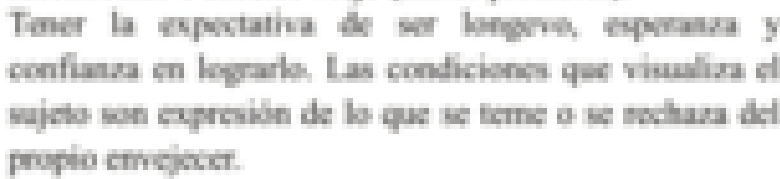 \\
\hline 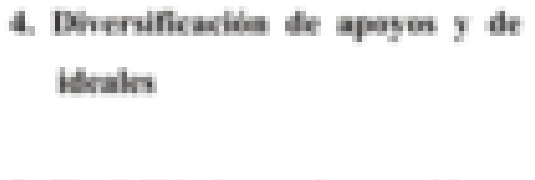 & 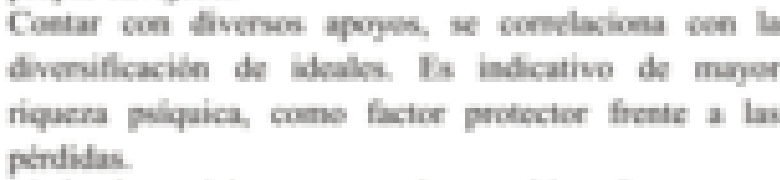 \\
\hline 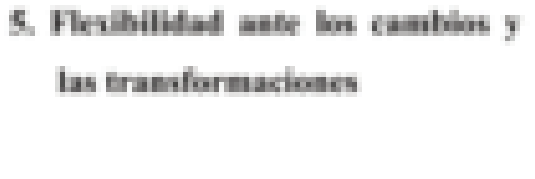 & 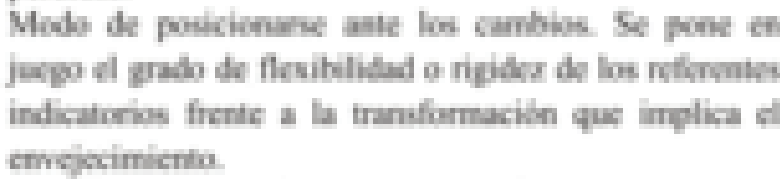 \\
\hline 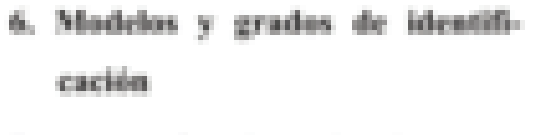 & 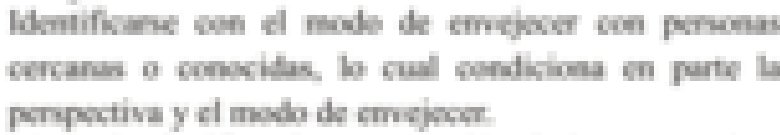 \\
\hline 2. Antaramia y drpadrefis & 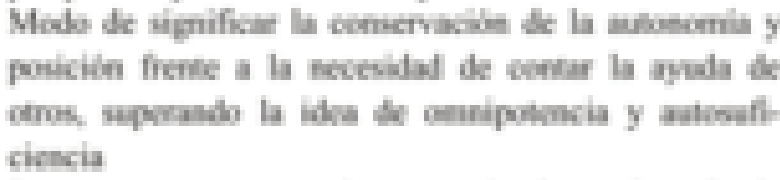 \\
\hline 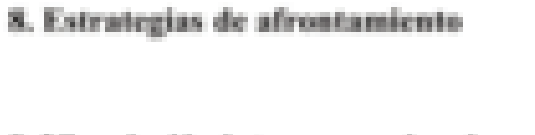 & 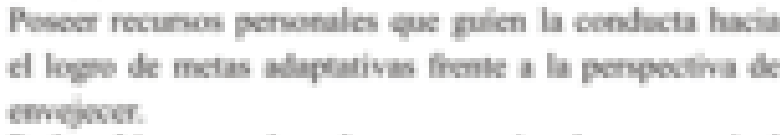 \\
\hline 4. Theularkn inierparrachas & 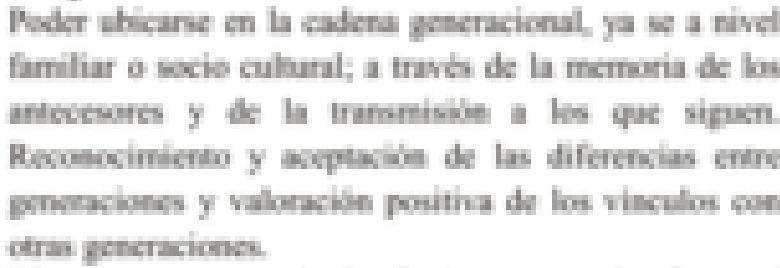 \\
\hline 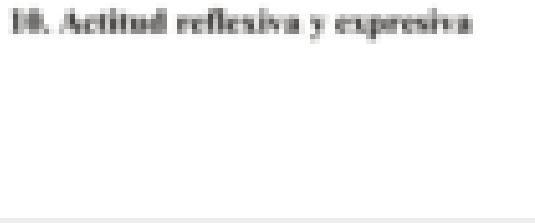 & 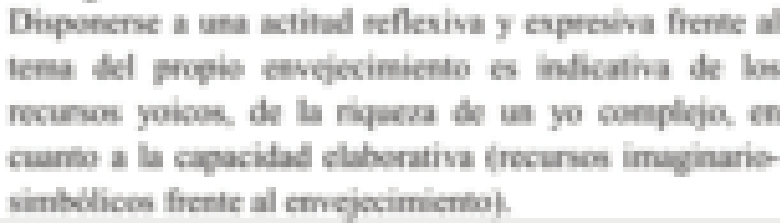 \\
\hline
\end{tabular}




\section{Cuadro 3}

Clasificación de categorías de análisis

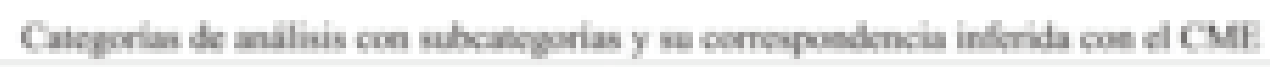

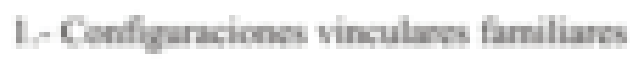

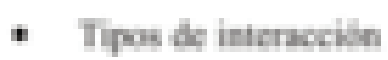

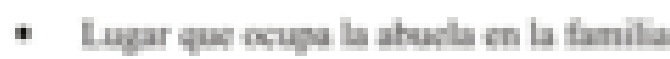

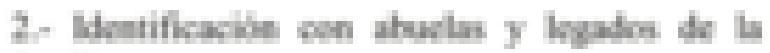
furnilis

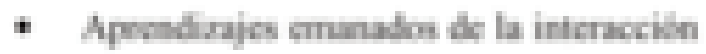
nitu- ahylu

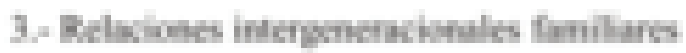

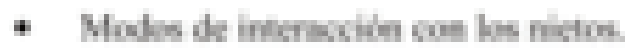

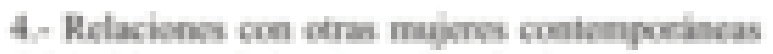

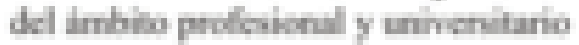

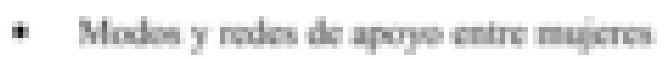

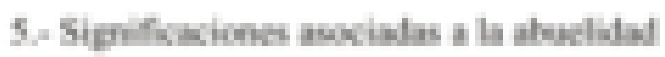

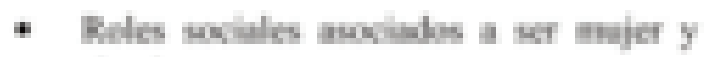
Heisli.

d.- Munas formus dh wr ahula

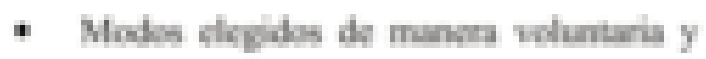

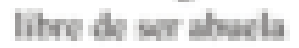

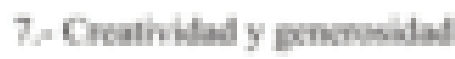

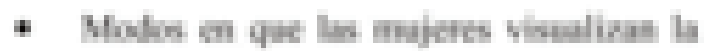
murcei mi whirin y apmerin di clas
Mhombis y dpondmolu

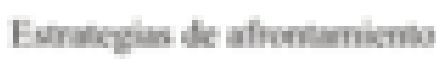

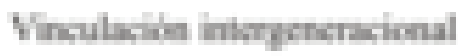

Tombeitu idmitars

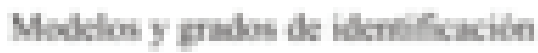

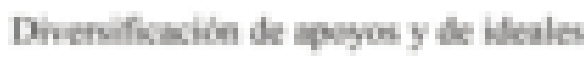

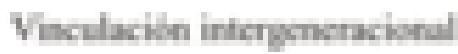

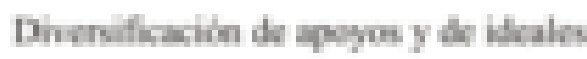

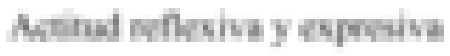

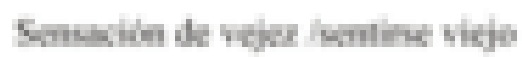

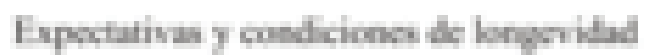

Thubilud wh lon carritas $y$ las Handomisiones

Aritud refoha y eqpoina

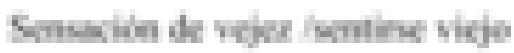

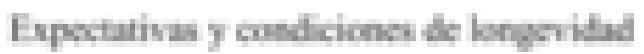

Aarmaly yowholi

Acthd reflains y apresina 


\section{Referencias bibliográficas}

Arditi, R. (1999). Searching for life. The grandmothers of the Plaza de Mayo and the disappeared children of Argentina. University of California Press.

Berenstein, I. (1991). Reconsideración del concepto de vínculo [Reconsideration of the concept of bond]. Psicoanálisis, 13(2), 219235.

Blanco García, A. I. (2007). ¿Con qué sueña una feminista? Sobre conciliación de vida laboral y familiar [What does a feminist dream about? On reconciliation of work and family life]. Revista Internacional de Ciencias Sociales y Humanidades, SOCIOTAM, XVII(1), 47-65. Recuperado el 8 de abril 2015 de http://www.redalyc.org/articulo.oa?id=65417103

Blázquez, G.N. \& Bustos, R.O. (2013). Saber y poder. Testimonios de directoras de la UNAM [Knowledge and power. Testimonies of directors of the UNAM]. México: Editorial UNAM.

Briones, E. \& Tabernero, C. (2005). Formación cooperativa en grupos heterogéneos [Cooperative formation in heterogeneous groups]. Psicothema, 17, 396-403. Recuperado el 17 de marzo de 2015 de http:// www.psicothema.com/pdf/3119.pdf.

Burin, M. (2000). Reinventar abuelidades [Reinventing grandparents]. Foro de psicoanálisis y género. Recuperado el 11 de enero de 2017 de http://dspace.uces.edu.ar:8 180/xmlui/bitstream/handle/123456789/ 1519/Burin_2000_Foro_Reinventar.pdf?sequence $=1$

Calasanti, T. (2004). New directions in feminist gerontology: An introduction. Journal of Aging Studies, 18, 1-8. Recuperado el 20 de abril de 2015 de http://journals.sagepub. com/doi/abs/10.1177/0891243204267958

Castañeda, P., Sánchez, D., Sánchez, A. \& Blanc S. (2004). Cómo perciben los nietos adultos las relaciones con sus abuelos [How adult grandchildren perceive relationships with their grandparents]. Anuario de Psicología, 35(1), 107-123. Recuperado el 18 de abril de 2015 de http://www.raco.cat/ index.php/anuariopsicologia/article/viewFil e/61781/88565

Castro, M. (2007). Relaciones intergeneracionales y bienestar de las personas mayores [Intergenerational relations and well-being of the elderly]. Tesis Doctoral. Editorial de la Universidad de Granada. Recuperado el 8 de abril de 2015 de http://digibug.ugr. es/bitstream/10481/1634/1/1684256x.pdf.

Celdrán, M. (2004). Relaciones intergeneracionales no normativas: La relación de los nietos con los abuelos afectados por una enfermedad neurodegenerativa [Non-normative intergenerational relationships: The relationship of grandchildren to grandparents affected by a neurodegenerative disease]. Revista Multidisciplinar de Gerontología, 14(5), 262-268. Recuperado el 17 de marzo de 2015 de https://www.researchgate.net/publication/28080494_Relaciones intergeneracionales_no_normativas_la_relacion_de_los_nietos_con_sus_abuelos_afe ctados_por_una_enfermedad_neurodegenerativa.

Coria, C., Freixas, A. \& Covas, S. (2005). Los cambios en la vida de las mujeres. Temores, mitos $y$ estrategias [Changes in the lives of women. Fears, myths and strategies]. Barcelona: Paidós.

Covarrubias, V.F. \& Brito, T.O. (2007). Una pálida sobra: La identidad del profesor mexicano [A pale leftover: The identity of the Mexican professor]. México: Universidad Pedagógica Nacional. Recuperado el 18 de marzo de 2015 de www.upn.mx/.../librosversion-digita $1 \% 3 \mathrm{~F}$ down 1 oad $\% 3$ D108\%253Auna-palida-sombra

Cruikshank, M. (2003). Learning to be old. Gender, culture, and aging. Lanham: Rowman \& Littlefield. Recuperado el 17 de 
marzo de 2015 de https://gerontologist.oxfordjournals.org/content/43/3/420.full.pdf

De Jong Gierveld, J., Dykstra, P. A. \& Schenk, N. (2012). Living arrangements, intergenerational support types and older adult loneliness in Eastern and Western Europe. Demographic Research, 27. Recuperado el 11 de abril de 2015 de https:/www.demographic-research. org/volumes/vol27/7/277.pdf

Diale, A., Longobardi, C. \& Sclavo, E. (2008). La relación abuelo-nieto: La percepción de los niños de la escuela primaria Università di Torino [The grandfather-grandson relationship: the perception of the children of the primary school Università di Torino]. International Journal of Developmental and Educational Psychology, (358), 357-366. Recuperado el 20 de abril de 2015 de http://infad.eu/RevistaINFAD/2008/n1/volumen1/INFAD_010120_357-366.pdf http://doi.org/10.1016/j.jaging.2003.09.001

Fernández, C. M. R. A. (2010). El pensamiento feminista de Edith Stein: Sus conferencias sobre la mujer (Alemania 1930) y nuestras mujeres mayores (España 2006-2007) [Edith Stein's Feminist Thinking: Her conferences on woman (Germany 1930) and our elderly women (Spain 2006-2007)]. Tesis doctoral, Universidad Complutense de Madrid, España. Recuperado el 17 de enero de 2017 de http://eprints.ucm.es/10816/1 /T30884.pdf

Freixas, A. (2005). Abuelas, madres, hijas. La transmisión sociocultural del arte de envejecer [Grandmothers, mothers, daughters. Sociocultural transmission of the art of aging]. Córdoba: Universidad de Córdoba. Icaria.

Freixas, F. A. (2007). Nuestra menopausia. Una versión no oficial [Our menopause. An unofficial version]. Barcelona: Paidós.

Freixas, F.A. (2008). La vida de las mujeres mayores a la luz de la investigación geron- tológica feminista [The life of older women in the light of feminist gerontological research]. Anuario de Psicología, 39(1), 41-57. Recuperado el 17 de enero de 2017 de http://revistes.ub.edu/index.php/Anuariopsicologia/article/view/8393/10357

Freud, S. (1916). Lo inconsciente [The unconscious]. Obras completas (Tomo 14). Buenos Aires: Amorrortu.

Galeano, E. (2015). Mujeres [Women]. México: Siglo XXI.

Galhardi de Pujalt, R.M.A. (2007). Conciliación entre la vida familiar y la vida laboral [Reconciliation of family and working life]. Revista Latinoamericana de Derecho Social, 4, 77-93. Recuperado el 11 de enero de 2017 de http://www.redalyc. org/articulo.oa? id=429640259004

Gannon, L. (1999). Women and aging. Transcending the myths. London: Routledge.

Garber, M.P. (2006). El rol desde una perspectiva vincular [Role from a linking perspective]. Reflexiones, 85(1), 2. Recuperado el 11 de enero de 2017 de http://www.redalyc.org/articulo.oa?id=72920817012.

Garzón, M.M.T. \& Mendoza, N.C. (2007). Mundos en disputa. Intervenciones en estudios culturales [Worlds in dispute. Interventions in cultural studies]. Bogotá: Editorial Javeriana.

Góngora, C. E. (2012). La abuelidad en el contexto de crianza [Abuelity in the parenting context]. Revista Crianza y Salud, 10(3), 812. Recuperado el 12 de marzo de 2015 de http://crianzaysalud.com.co/wpcontent/uploads/2013/10/crianza 10 3_baja.pdf

González, B.J., González S.J., De la Fuente A.R, Marquínez, M.S. \& González, B.N. (2010). Funciones que desempeñan los abuelos [Functions performed by grandparents], International Journal of Developmental and Educational Psychology INFAD Revista de Psicología, 2, 625-633. Recupe- 
rado el 18 de enero de 2017 de http:// dehesa.unex.es/bitstream/handle/10662/ 3144/0214-9877_2010_1_2_625.pdf?sequence $=1$

González, J. \& De La Fuente, R. (2008). Relevancia psicosocio-educativa de las relaciones generacionales abuelo-nieto [Psychosocial and educational relevance of generational relationships grandfather-grandson]. Revista Española de Pedagogía, (239), 103-118. Recuperado el 2 de junio de 2015 de http://revistadepedagogia.org/.../3-relevancia-psico-socio-educativa-de-las-relaciones.

González, M.M.L. (2015). Graciela Hierro. Historia de una feminista, abriendo camino a la educación de las mujeres [Graciela Hierro. History of a feminist, paving the way for women's education], Mujeres, Derecho y Sociedad, 11(21), 108-119. Recuperado el 13 de enero de 2017 de www.femumex.org/docs/revistaDigital/ Revista_Segunda_Edicion_Especial2015. pdf

Gullette, M.M. (1997). Declining to decline: Cultural combat and the politics of the midlife. Charlottesville, VA: University of Virginia.

Hemilse Acevedo, M. (2011). El proceso de codificación en investigación cualitativa [The coding process in qualitative research], Contribuciones a las Ciencias Sociales, 12. Recuperado el 11 de enero de 2017 de www.eumed.net/rev/cccss/12/

Hernández S.R., Fernández C.C. \& Baptista L.P. (2006). Metodología de la investigación [Investigation methodology] ( $4^{\mathrm{a}}$ ed.). México: McGraw Hill.

Herrera, M. \& Tenembaum, E. (2007). Identidad despojo y restitución [Identity dispossess and restitution]. Buenos Aires: Abuelas de Plaza de Mayo.

Hierro, G. (1990). De la domesticación a la educación de las mujeres [From domestica- tion to women's education]. México: Editorial Torres Asociados.

Hierro, G. (2000). Gracias a la vida [Thanks to life]. México: Premios DEMAC.

Holstein, M. B. (2006). On being an aging woman. En T. Calasanti (Ed.), Age matters. Realigning feminist thinking (pp. 313-334). New York: Routledge.

Iacub, R. \& Sabatini, B. (s/f). Módulo 3: Psicología de la mediana edad y vejez [Module 3: Psychology of middle age and old age]. Mar de la Plata: Universidad de Mar de la Plata. Recuperado el 11 de abril de 2015 de https://www.desarrollosocial. gob.ar/wp-content/uploads/2015/05/ Gerontolog--a-Comunitaria-Modulo-31.pdf

Juliano, D. (2005). El saber de las mujeres [The knowledge of women]. En A. Freixas Abuelas, madres, hijas. La transmisión sociocultural del arte de envejecer [Grand mothers, mothers, daughters. Sociocultural transmission of the art of aging]. Barcelona: Icaria/Universidad de Córdoba. Recuperado el 17 de enero de 2017 de https://dialnet.unirioja.es/servlet/libro? codigo $=6768$

Kahana, E. \& Kahana, B. (1971). Theoretical and research perspediveson grand parenthood. Aging and Human Development, 1(2), 261-268. http://journals.sagepub.com/ doi/ abs/10.2190/ AG.2.4.c

Kubissa, L.P. (1995). Pactos entre mujeres [Covenants between women]. En 10 palabras clave sobre mujer (pp. 331-365). Verbo Divino. Recuperado el 11 de enero de 2017 de http://www.mujeresenred.net/IMG/pdf/ pactos_mujeres.pdf

Lagarde, M. (1997). Los cautiverios de las mujeres: Madresposas, monjas, presas, putas y locas [The captives of women: Mothers, nuns, prey, whores and crazy]. México, DF: UNAM.

Lagarde, M. (2006). Pacto entre mujeres. Sororidad [Covenant between women. Sorority]. Aportes Para El Debate, 123-135. 
Recuperado el 18 de abril de 2015 de http://www.asociacionag. org.ar/pdfaportes/25/09.pdf

Lévi-Strauss, C. (1987). Polémica sobre el origen y la universalidad de la familia [Controversy over the origin and universality of family]. Barcelona: Anagrama.

Martínez, D.V. (2014). Sororidad [Sorority]. Folleto conmemorativo del Día Internacional de la Mujer: Departamento de Impulso Social y Empresarial de la Univer- sidad Intercontinental, 8-11. México: Direc- ción de General de Formación Continua de la Universidad Intercontinental.

Mead, G.H. (1983). Espíritu, persona y sociedad [Spirit, person and society]. Buenos Aires, Argentina: Paidós.

Mead, M. (1970). Cultura y compromiso [Culture and commitment]. Madrid: Gedisa.

Mikulic, I.M., Radusky, P. \& Crespi, M. (2015). Construcción y validación del inventario de competencias socioemocionales para adultos (icse) [Construction and validation of the inventory of socio-emotional competences for adults (ICSE)]. Interdisciplinaria, 32(2) 307-329. Recuperado el 11 de enero de 2017 de http:/www.redalyc. org/articulo.oa?id $=18043528007$

Minuchin, S. \& Fishman, H.C. (2001). Técnicas de terapia familiar [Family therapy techniques]. México: Paidós.

Minuchin, S., Nichols, M.P. \& Lee, W. (2011). Evaluación de familias y parejas. Del sintoma al sistema [Evaluation of families and couples. From symptom to system]. México: Paidós.

Miralles. I. (2010). Vejez productiva. El reconocimiento de las personas mayores como un recurso indispensable en la sociedad [Productive old age. Recognition of older people as an indispensable resource in society]. Revista de Temas Sociales Kairos, 14(26), 1-14. Recuperado el 17 de enero de 2017 de https://dialnet.unirioja.es/servlet/articulo? codigo $=3702472$
Montpetit, M.A., Nelson, N.A. \& Tiberio, S. S. (2016). Daily interactions and affect in older adulthood: Family, friends, and perceived support. Journal of Happiness Studies, 18(2), 1-16. http://dx.doi.org/10.1007/ s10902-016-9730-4

Muller, F.J. \& Bermejo, F. (2016). Los temas de la memoria colectiva del golpe de estado de 1976 en Argentina en función de la ideología y las generaciones [The themes of the collective memory of the 1976 coup d'etat in Argentina in terms of ideology and generations]. Interdisciplinaria, 33(1), 41-63. Recuperado el 11 de enero de 2017, de http://www.scielo.org.ar/scielo. php? script $=$ sci_arttext $\&$ pid $=S 1668$ $70272016000100003 \& \operatorname{lng}=\mathrm{es} \& \mathrm{t} \operatorname{lng}=\mathrm{es}$. scielo.org.ar/scielo.php?script=sci_arttext\&pi $\mathrm{d}=\mathrm{S} 1668-70272016000100003 \& \operatorname{lng}=$ es\&tlng $=$ es.

Neugarten, B. (1999). Los significados de la edad [The meanings of age]. Barcelona: Herder.

Neugarten, B. \& Weistein, K. (1964). The changing American grandparent. Journal of Marriage and Family, 26(2), 199-204. http://dx.doi.org/10.2307/349727

Orosa, T. (Ed.). (2014). Temas de Psicogerontología [Topics of Psychogeron- tology]. La Habana: Universidad de la Habana.

Osuna, M. J. (2006). Relaciones familiares en la vejez: vínculos de los abuelos y de las abuelas con sus nietos y nietas en la infancia [Family relations in old age: Links between grandparents and grandmothers with their grandchildren in childhood]. Revista Multidisciplinar Gerontología, 16(1), 16-25. Recuperado el 12 de enero de 2017 de https://www.researchgate.net/publication/28111378

Palermo, A. I. (2006). El acceso de las mujeres a la educación universitaria [Women's access to university education]. Revista Argentina de Sociología, 4(7), 11-46. Recuperado 
el 11 de enero de 2017 de http://www.scielo. org.ar/scielo.php?script $=$ sci_arttext\&pid $=\mathrm{S} 1$ 669-32482006000200002\&lng=es\&tlng=es.

Patton, M.Q. (1990). Qualitative evaluation and research methods (2da. ed.). Newbury Park, CA: Sage.

Pérez, O.L. (2007). Las abuelas como recurso de conciliación entre la vida familiar y laboral. Presente y futuro [Informe de investigación]. Madrid: Instituto de la Mujer, Ministerio de Trabajo y Asuntos Sociales. Recuperado el 11 de enero de 2017 de http://189.209.180.187/bibliotecageriatria/acervo/pdf/perez-abuelas.pdf.

Pérez. S.L., Oropeza. T.R., López, P.J. \& Colúnga, R.C. (2014). Psicogerontología y trabajo anticipado del envejecer [Psychogerontology and early work of aging]. Revista Iberoamericana de Ciencias, 1(2), 3-11. Recuperado el 15 de enero de 2017 de http://www.reibci.org/publicados/2014/julio /2200123.pdf

Pinazo, S. \& Lluna, J. (2011). Menores criados por sus abuelas. Mejora de la pautas de cuidado a menores en acogimiento familiar en familia extensa a través de un programa de intervención psicoeducativo [Minors raised by their grandmothers. Improvement of care guidelines for children in foster care in the extended family through a psychoeducational intervention program]. Revista sobre la Infancia y la Adolescencia, (1), 14-34. Recuperado el 18 de marzo de 2015 de http://dx.doi.org/10.4995/reinad.2011.834.

Redler. P. (1986). Abuelidad. Más allá de la paternidad [Grandparents. Beyond paternity]. Buenos Aires: Legasa.

Rico, C., Serra, E. \& Viguer, P. (2001). Abuelos $y$ nietos. Abuelo favorito, abuelo útil [Grandparents and grandchildren. Favorite grandfather, useful grandfather]. Madrid: Pirámide.

Riviere, M. (2000). El mundo según las mujeres [The world according to women]. Madrid: Aguilar.
Rodríguez Gómez, G. (1996). Metodología de la investigación cualitativa [Methodology of qualitative research]. Archidona, Málaga: Ed. Aljibe.

Rodríguez, R.P. (2002). Mujeres mayores, género y protección social (o adonde conduce el amor) [Older women, gender and social protection (or where love leads)]. En V. Maquieira (Ed.), Mujeres mayores en el siglo XXI. De la invisibilidad al protagonismo [Older women in the $21 \mathrm{st}$ century. From invisibility to protagonism]. Madrid: IMSERSO.

Ross, M. (1999). Planning and the heritage. Londres: E.F.N. Spon.

Ruiz-Alberti, C. (2010). El pensamiento feminista de Edith Stein: Sus conferencias sobre la mujer (Alemania 1930) y nuestras mujeres mayores (España 2006-2007) [Edith Stein's Feminist Thinking: Her conferences on woman (Germany 1930) and our elderly women (Spain 2006-2007)]. Tesis Doctoral no publicada. Universidad Complutense de Madrid, España. Recuperado el 10 de enero de 2017 de http://eprints.ucm.es/10816/1/T 30884.pdf

Ruiz, M., Pineda, O. \& Valencia, S. (2009). Los abuelos favoritos desde la percepción de preadolescentes de la ciudad de Armenia. Los abuelos favoritos desde la percepción de preadolescentes de la ciudad de Armenia [The favorite grandparents from the perception of preadolescents of the city of Armenia. The favorite grandparents from the perception of pre-adolescents of the city of Armenia]. Revista Investigativa, Universidad de Quindio, (19), 28-41. Armenia-Colombia. Recuperado el 13 de marzo de 2015 de http://es.scribd.com/doc/ 69020398/Revista-Universidad-DelQuindio-2009-1.

Salvarezza, L. (1998). La vejez, una mirada gerontológica actual [The old age, a current gerontological view]. Buenos Aires: Paidós. 
Sanz, P., Mula, J. \& Moril, R. (2011). La relación abuelos-nietos-escuela: Una excusa o una necesidad [The grandparent-grandchildschool relationship: An excuse or a need]. Trabajo presentado en el XII Congreso Internacional de Teoría de la Educación. Universidad de Barcelona. Recuperado el 11 de enero de 2017 de http://www.cite2011. com/Comunicaciones/Familias/142.pdf.

Serdio. S. C. (2007). El ejercicio femenino del cuidado: Del escenario familiar al escenario educativo [The female exercise of care: From the family stage to the educational scenario]. Papeles Salmantinos de Educación, 9, 231-254. Recuperado el 11 de enero de 2017 de https://dialnet.unirioja. es/servlet/autor?codigo $=851860$.

Serdio. S.C. (2012). Mujeres y educación: Transformación y saberes femeninos [Women and education: Transformation and feminine knowledge]. Papeles Salmantinos de Educación, 16, 45-65. Recuperado el 12 de enero de $2017 \mathrm{de} \mathrm{http://summa.upsa.es/vie-}$ wer.vm? id $=0000030886 \&$ page $=1 \&$ se arch=\&lang=es\&view=main

Sims, M. \& Rofail, M. (2014). Grandparents with little or no contact with grandchildrenimpact on grandparents. Aging Sci, 2(117), 2-7. Recuperado el 23 de enero de 2017 de http://dx.doi.org/10.4172/23298847.1000117.

Sontag, S. (1982). Mujeres: Un doble patrón para envejecer [Women: A double standard for aging.]. Revista Femenismo, 38(24).

Strauss, A. \& Corbin, J. (2002). Codificación abierta [Open coding]. En Bases de la investigación cualitativa. Técnicas y procedimientos para desarrollar la teoría fundamentada (Cap. 8). Medellín: Editorial Universidad de Antioquía.

Strauss, A. \& Corbin, J. (2002). Codificación selectiva [Selective coding]. En Bases de la investigación cualitativa. Técnicas y procedimientos para desarrollar la teoría funda- mentada (Cap. 10). Medellín: Editorial Universidad de Antioquía.

Tannenbaum, Cara B., Nasmith, L. \& Mayo, N. (2003). Understanding older women's health care concerns: A qualitative study. Journal of Women \& Aging, 15(4), 103-116. http://dx.doi.org/10.1300/J074v15n04_09

Taylor, S. \& Bodgan, R. (1986). El trabajo con los datos. Análisis de los datos en la investigación cualitativa [Working with data. Analysis of data in qualitative research]. En Introducción a los métodos cualitativos de investigación (Cap. 6). Buenos Aires: Paidós.

Tobio, C. (2002). Cambio social y solidaridad entre generaciones de mujeres [Social change and solidarity between generations of women]. En D. Maquiera (Comp.), $\mathrm{Mu}$ jeres mayores en el siglo XXI (pp. 207-229). Madrid: Ministerio de Trabajo y Asunto Sociales. Recuperado el 12 de enero de 2017 de http://envejecimiento.csic.es/documentos/documentos/maquieira-mujeres-01.pdf

Triadó, C., Martínez, G. \& Villar, F. (2000a). El rol del abuelo: Cómo perciben los abuelos las relaciones con sus nietos [The role of grandfather: How grandparents perceive relationships with their grandchildren]. Revista Española de Geriatría y Gerontología, 35(52), 30-36. Recuperado el 11 de marzo de 2015 de http://www.infogerontologia.com/documents/ gerontologia/ articulos/11_congreso_geront_geriat_cataluna/2000c_rol_de_abuelo.pdf

Triadó, C., Martínez, G. \& Villar, F. (2000b). El rol y la importancia de los abuelos para sus nietos adolescentes [The role and importance of grandparents for their teenage grandchildren]. Anuario de Psicología, 31(2), 107-118. Recuperado el 11 de marzo de 2015 de http://www.raco.cat/index.php/ AnuarioPsicologia/article/view/61547/88402

Twigg, J. (2004). The body, gender, and age: Feminist insights in social gerontology. Journal of Aging Studies, 18(1), 59-73. 
Recuperado el 18 de enero de 2017 de https://www.researchgate.net/publication/222062808_The_Body_Gender_and_Ag e_Feminist_Insights_in_Social_Gerontology Van Rast, N., Verschueren, K. \& Marcoen, A. (1995). The meaning of grandparents as viewed by adolescent grandchildren: An empirical study in Belgium. International Journal of Aging and Human Development, 41, 311-324. https://doi.org/10.2190/PPLVDWG7-HV9R-6LVB

Villalba, C. (2001). Análisis de la población de abuelas cuidadoras en la provincia de Sevilla. Contextos sociofamiliares, redes de apoyo social y riesgos psicosociales. [Analysis of the grandmothers of caregivers in the Province of Seville. Social-family contexts, social support networks and psychosocial risks]. Tesis doctoral. Universidad de Sevi1la. Recuperado el 11 de enero de 2017 de http://fondosdigitales.us.es/tesis/tesis/561/ analisis-de-abuelas-cuidadoras-en-la-provi/.

Wellard, S. (2013). Policy briefing 04 grandparents and childcare. Grandparents plus. Recuperado el 20 de enero de 2017 de http:// www.grandparentsplus.org.uk/wpcontent/up
loads/2013/05/Briefing-paper-on-grandparental-childcare.pdf

Witt, K. (2005). Las reinas. Protagonistas y agentes activas de su madurez [The queens. Protagonists and active agents of their maturity]. La Jornada UNAM. Nota de prensa. Recuperado el 20 de enero de 2017 de http://www.jornada.unam.mx/2005/07/04/in formacion/83 reinas.htm.

Yerro, T. (2013). Abuelas y abuelos españoles de hoy: ¿Imprescindibles? [Spanish grandmothers and grandparents today: essential?]. Cuadernos Gerontológicos, (15). Recuperado el 11 de enero de 2017 de https:// www.unav.edu/documents/29032/ 472618/cuadernos-gerontologicos-15.pdf.

Zarebski, G. (2005). Hacia un buen envejecer [Towards a good old age]. Buenos Aires: Universidad Maimónides.

Zarebski, G. (2008). Padre de mis hijos. ¿Padre de mis padres? [Father of my children. Father of my parents?]. Buenos Aires: Paidós.

Zarebski, G. (2011). Cuestionario Mi Envejecer [My Aging Questionnaire]. Buenos Aires: Paidós. 
Abuelas universitarias 